\title{
Liposomes as Adjuvants and Vaccine Delivery Systems
}

\author{
D. S. Tretiakova ${ }^{a}$ and E. L. Vodovozova ${ }^{a, *}$ \\ ${ }^{a}$ Shemyakin-Ovchinnikov Institute of Bioorganic Chemistry, Russian Academy of Sciences, Moscow, 117997 Russia \\ *e-mail: elvod@lipids.ibch.ru \\ Received September 19, 2021; revised September 22, 2021; accepted September 24, 2021
}

\begin{abstract}
The review considers liposomes as systems of substantial interest as adjuvant carriers in vaccinology due to their versatility and maximal biocompatibility. Research and development on the use of liposomes and lipid nanoparticles to create subunit vaccines for the prevention and treatment of infectious diseases has been going on for several decades. In recent years, the area has seen serious progress due to the improvement of the technology of industrial production of various high-grade lipids suitable for parenteral administration and the emergence of new technologies and equipment for the production of liposomal preparations. When developing vaccines, it is necessary to take into account how the body's immune system (innate and adaptive immunity) functions. The review briefly describes some of the fundamental mechanisms underlying the mobilization of immunity when encountering an antigen, as well as the influence of liposome carriers on the processes of internalization of antigens by immunocompetent cells and ways of immune response induction. The results of the studies on the interactions of liposomes with antigen-presenting cells in function of the liposome size, charge, and phase state of the bilayer, which depends on the lipid composition, are often contradictory and should be verified in each specific case. The introduction of immunostimulant components into the composition of liposomal vaccine complexes-ligands of the pathogen-associated molecular pattern receptors-permits modulation of the strength and type of the immune response. The review briefly discusses liposomebased vaccines approved for use in the clinic for the treatment and prevention of infectious diseases, including mRNA-loaded lipid nanoparticles. Examples of liposomal vaccines that undergo various stages of clinical trials are presented.
\end{abstract}

Keywords: liposomes, vaccines, adjuvants, immunostimulants, infectious diseases

DOI: $10.1134 /$ S1990747822020076

\section{INTRODUCTION}

The increased awareness of the risks of pandemics and their devastating socioeconomic consequences for individual states and the world as a whole emphasizes the relevance of the development of effective and safe means for the treatment and prevention of viral infections. The world scientific community has begun the accelerated development of vaccines capable of activating both cellular and humoral immunity and forming long-term immunological memory. Traditional

Abbreviations: APCs, antigen-presenting cells; Chol, cholesterol; CpG-ODN, oligodeoxyribonucleotide containing the CpG motif; CTL, cytotoxic T lymphocytes; DC, dendritic cells; DDA, dioctadecyl dimethylammonium (bromide); DOPC, dioleoylphosphatidylcholine; DOPE, dioleoylphosphatidylethanolamine; DOTAP, dioleoyl trimethylammonium propane; DPPC, dipalmitoylphosphatidylcholine; DSPC, distearoylphosphatidylcholine; ePC, egg phosphatidylcholine; ePG, egg phosphatidylglycerol; IFN- $\gamma$, interferon gamma; IFN- $\alpha$, interferon alpha; IgG, immunoglobulins G; IL, interleukin; MHC, major histocompatibility complex; OVA, egg ovalbumin; PA, phosphatidic acid; PAMP, pathogen-associated molecular patterns; PC, phosphatidylcholine; PG, phosphatidylglycerol; PRRs, pattern recognition receptors; PS, phosphatidylserine; $\mathrm{T}_{\mathrm{H}}$, T helper cells; TCR, T-cell receptor; TDB, trehalose-6, 6'dibehenate; TLRs, toll-like receptors. vaccines are live attenuated or inactivated/killed pathogens. They do not need adjuvants, since they contain not only antigens, but also other components of bacterial or viral origin, which effectively activate several components of the innate immune system at once. However, the risk of developing allergic and autoimmune reactions in response to administration of such agents, as well as the difficulties of creating, producing, and transporting some vaccines based on them, stimulated the development of other vaccine strategies [1]. Subunit vaccines usually contain only surface antigens (proteins or peptides), which reduces the protein content of the vaccine and thus its allergenic potency, but such vaccines are less immunogenic. Packaging of antigens into particles comparable in size to viruses or bacteria (from hundreds of nanometers to several micrometers) allows overcoming the disadvantages of these vaccines and provides additional advantages [2, 3]: antigens are protected from premature degradation; their capture by antigen-presenting cells is stimulated by passive or targeted transport; a depot for prolonged presentation of antigens is provided; and simultaneously delivery of antigens and adjuvants/immunostimulants to the cell is enabled, 
which makes it possible to control the type (humoral or cellular) of the immune response. This review considers liposomes as systems of significant interest as adjuvant carriers in vaccinology due to their multifunctionality and high biocompatibility. The ability of liposomes to induce an immune response to antigens encapsulated in the internal volume or associated with the surface has first been described by Allison and Gregoriadis [4, 5]. Since then, research and development on the use of liposomes and lipid nanoparticles (LNPs, non-vesicular supramolecular systems, as opposed to classical liposomes) for the development of vaccines to prevent and treat infectious and oncological diseases have been developing (reviews [2, 6-9]). Liposomal vaccines against influenza, hepatitis A viruses, malaria, and Varicella zoster virus (Inflexal ${ }^{\circledR}$, Epaxal ${ }^{\circledR}$, Mosquirix ${ }^{\circledR}$ and Shingrix ${ }^{\circledR}$, respectively) are now commercially available; a number of liposomal preparations are undergoing clinical trials as prophylactic and therapeutic vaccines against malaria, influenza, tuberculosis, HIV, Dengue fever [6-10], etc. Vaccines based on liposomes are safe and often highly effective. For example, Epaxal ${ }^{\circledR}$, when administered as a single dose to infants, has shown $100 \%$ protection with no side effects, in contrast to traditional vaccinations with aluminum-containing vaccines, which provide only $66.6 \%$ protection and require re-vaccination [11]. The Shingrix ${ }^{\circledR}$ (GlaxoSmithKline) vaccine offers $90 \%$ protection against shingles [12]. Finally, the SARS-CoV-2 virus pandemic, which has swept the world over the past 2 years, has contributed to the intensive development, rapid commercialization, and clinical introduction of highly effective preventive vaccines based on lipid nanoparticles and mRNA of the virus S-protein (Pfizer/BioNTech and Moderna).

The advantage of liposomal delivery systems lies in their flexibility, that is, the possibility of creating a wide variety of structures depending on the chemical properties of antigen molecules and the type of immune response required. The composition of lipids, charge and size of liposomes or LNPs, and the localization of antigens or adjuvants in the supramolecular complex of the vaccine can be varied. Water-soluble antigens-proteins, peptides, nucleic acids, and/or carbohydrates-are encapsulated in the internal aqueous volume of liposomes while lipophilic/amphiphilic substances, including lipopeptides, glycolipids, adjuvants, etc., are embedded in the lipid bilayer. Antigens also associate with the surface of liposomes by adsorption or covalent binding, and different types of antigens and immunostimulatory adjuvants can be combined in one preparation [13, 14]. Nevertheless, it should be borne in mind that liposomes, like other vaccine preparations, depending, for example, on the route of administration into the body, can also cause undesirable effects mediated by the immune system, such as hypersensitivity, immunosuppression, etc. [15, 16].
The review briefly discusses some of the fundamental mechanisms underlying the mobilization of the immune system when it encounters an antigen; the effect of carrier liposomes on the processes of internalization of antigens by immunocompetent cells; and the pathways for inducing an immune response. Then, examples of liposome-based vaccines for the treatment and prevention of infectious diseases are presented.

\section{FACTORS OF INNATE AND ADAPTIVE IMMUNITY}

Innate immunity, the first line of the body defense system against pathogens, is made up of proteins of the complement system and phagocytes, which are activated when they recognize pathogen-associated molecular patterns (PAMP) through pattern recognition receptors (PRR) expressed thereon and trigger adaptive immune response by presentation of antigens to T lymphocytes (thus being antigen-presenting cells, APCs). The main APCs are dendritic cells, although macrophages can also perform this function [17]. A subgroup of PRRs, toll-like receptors (TLRs), on the surface of APCs recognize PAMP pathogens. Activation of TLRs plays the key role in the development of the innate immune response and is its hallmark [18].

The second line of defense, adaptive immunity, is implemented through specific immune responses to molecular determinants of pathogens as a result of activation of $\mathrm{T}$ lymphocytes-CD4+ T-helper $\left(\mathrm{T}_{\mathrm{H}}\right)$ cells and CD8+ cytotoxic T lymphocytes (CTLs) and $\mathrm{B}$ lymphocytes carrying antigen-specific receptors (BCR) on the surface. The most significant subpopulations of $T_{H}$ lymphocytes are $T_{H} 1$ and $T_{H} 2$ cells [18].

Dendritic cells (DCs) are derived from bone marrow progenitor cells. Immature DC circulates in peripheral tissues until it recognizes a foreign antigen by PRR, after which the DC ingests the antigen via phagocytosis or receptor-mediated endocytosis and migrates (in the process of homing) to lymph nodes. During homing, DCs mature. Maturation of DCs is accompanied by an increase in the presentation of major histocompatibility complex (MHC) molecules on their surface, a change in the expression pattern of chemokine receptors, an increased regulation of costimulatory molecules (CD80, CD86) and T-cell adhesion molecules (CD48, CD58), and the production of key cytokines, such as interleukin-12 (IL-12). During maturation, DCs cleave pathogens into small peptides-epitopes, which are presented on the surface of DCs (and other APCs) by class I or class II MHC molecules [19]. MHC complexes with epitopes are presented to naive $\mathrm{T}$ cells in the lymph nodes.

When a DC contacts a $\mathrm{T}$ cell, the peptide-MHC molecule complex is recognized by $\mathrm{T}$-cell receptors (TCRs) (Fig. 1). In addition to stimulating the TCR, in order to induce clonal expansion and differentiation 


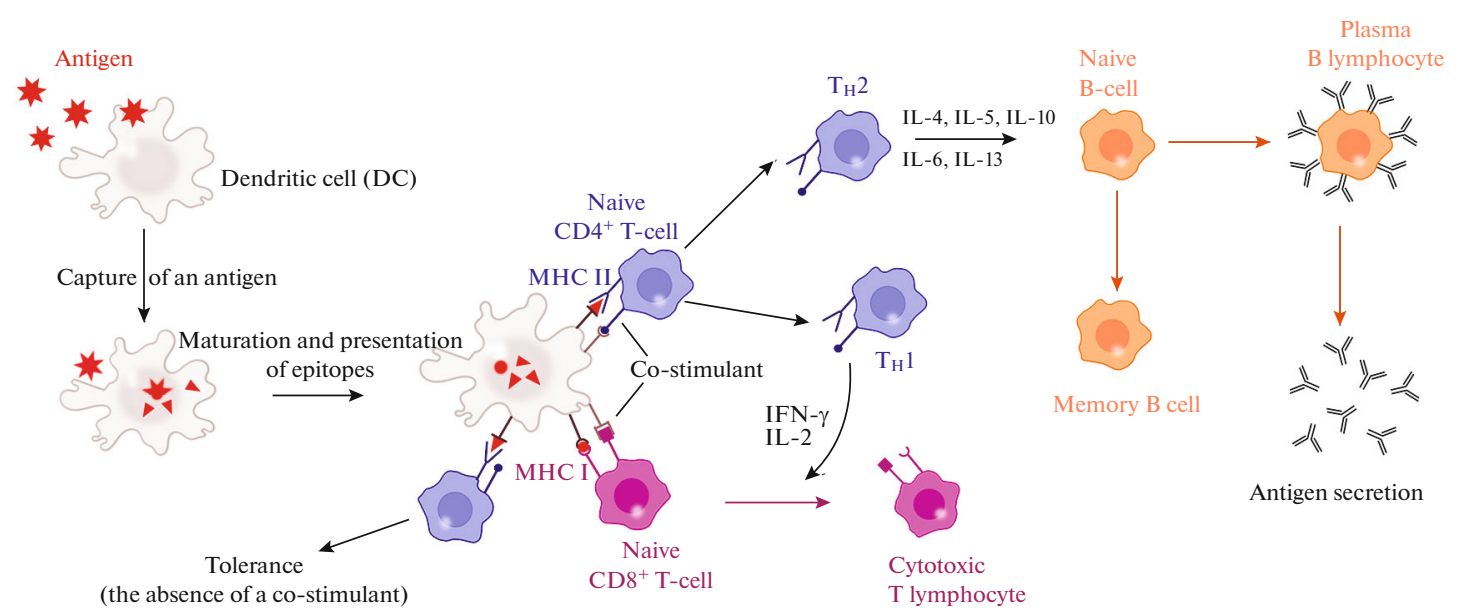

Fig. 1. Scheme of antigen presentation by dendritic cells and pathways of adaptive immunity activation.

into effector and memory cells, the $\mathrm{T}$ cell must receive a second, co-stimulatory signal. The absence of the latter leads to immunological tolerance [2]. The peptide-MHC class I complexes stimulate naive CD8+ T lymphocytes, converting them into CTLs, which are responsible for cellular immunity and the destruction of infected cells. The peptide-MHC class II complexes activate naive $\mathrm{CD} 4+\mathrm{T}$ lymphocytes, which then proliferate and differentiate into $\mathrm{T}_{\mathrm{H}} 1$ and $\mathrm{T}_{\mathrm{H}} 2$ subpopulations depending on the type of infection. $\mathrm{T}_{\mathrm{H}} 1$ cells secrete cytokines interferon gamma (IFN- $\gamma$ ) and tumor necrosis factor alpha (TNF- $\alpha)$, which activate and regulate CTLs. $\mathrm{T}_{\mathrm{H}} 2$ cells interact with $\mathrm{B}$ lymphocytes and induce their differentiation into plasma and memory cells. Plasma B cells secrete antibodies that neutralize antigens/pathogens (humoral immunity), and memory B cells form immunological memory, which allows rapid recognition of the pathogen in case of re-infection.

After entering the phagolysosomes of APCs, exogenous antigens typically are directed to the cell compartments expressing MHC class II molecules, where peptide epitopes formed by proteolysis are loaded onto pre-formed MHC class II, and then this complex is presented on the cell membrane, while endogenous peptides that the proteasome generates from intracellular proteins are presented in a complex with MHC class I molecules. However, the phenomenon of crosspresentation-a way of presentation of exogenous antigens leading to a load on MHC class I moleculesallows stimulating cytotoxic $\mathrm{T}$ cells in response to an exogenous antigen. The unique ability of DCs and macrophages to carry out cross-presentation was discovered long ago [20]; however, there is still no exact understanding of the intracellular mechanism of this process. Cross-presentation can follow the vacuole and cytosol pathways (Fig. 2). The vacuole pathway is mediated by lysosomal proteases and includes a peptide exchange stage for reloading endosomal com- plexes with MHC class I molecules, which are then redirected directly back to the plasma membrane [21]. The cytosol pathway, which is considered the most important, depends on the transporter associated with antigen processing (TAP) and the proteasome (the antigen is exported to the cytosol due to the SEC61 translocon, which enters the membrane of antigencontaining endosomes from the endoplasmic reticulum [22]). A lot of data have been accumulated on the cross-presentation of antigens after the capture of various nanoparticle carriers by dendritic cells, which indicates that such vaccine systems, including liposomal ones, are promising for the induction of cellular immunity $[2,3,6]$.

\section{LIPOSOMES AND INNATE IMMUNITY}

Liposomes, like any particles of the size of viruses and bacteria, are actually adjuvants: they are recognized and internalized via phagocytosis or receptormediated endocytosis by APCs in peripheral tissues. The mechanism of action of liposomes as direct activators of the innate immune response is comprehensively reviewed in [9]. The important role of some phospholipids - the main components of the liposome membrane-as precursors of a number of secondary mediators is noted in modulating innate and adaptive immune responses through various mechanisms. Phospholipids play an essential role in the physiology and pathology of phagocytosis, a critical stage in the manifestation of innate immunity. Phagocytosis begins with the recognition of a particle by corresponding receptors and formation of a phagocytic cup, followed by the closure of the phagosome and its internalization (Fig. 2). The formation and maturation of a phagosome is accompanied by coordinated processes of signaling and intracellular targeted transport, which are regulated by lipids [23, 24]. Lipids of several classes (see below) concentrate in microdomains of the cell 


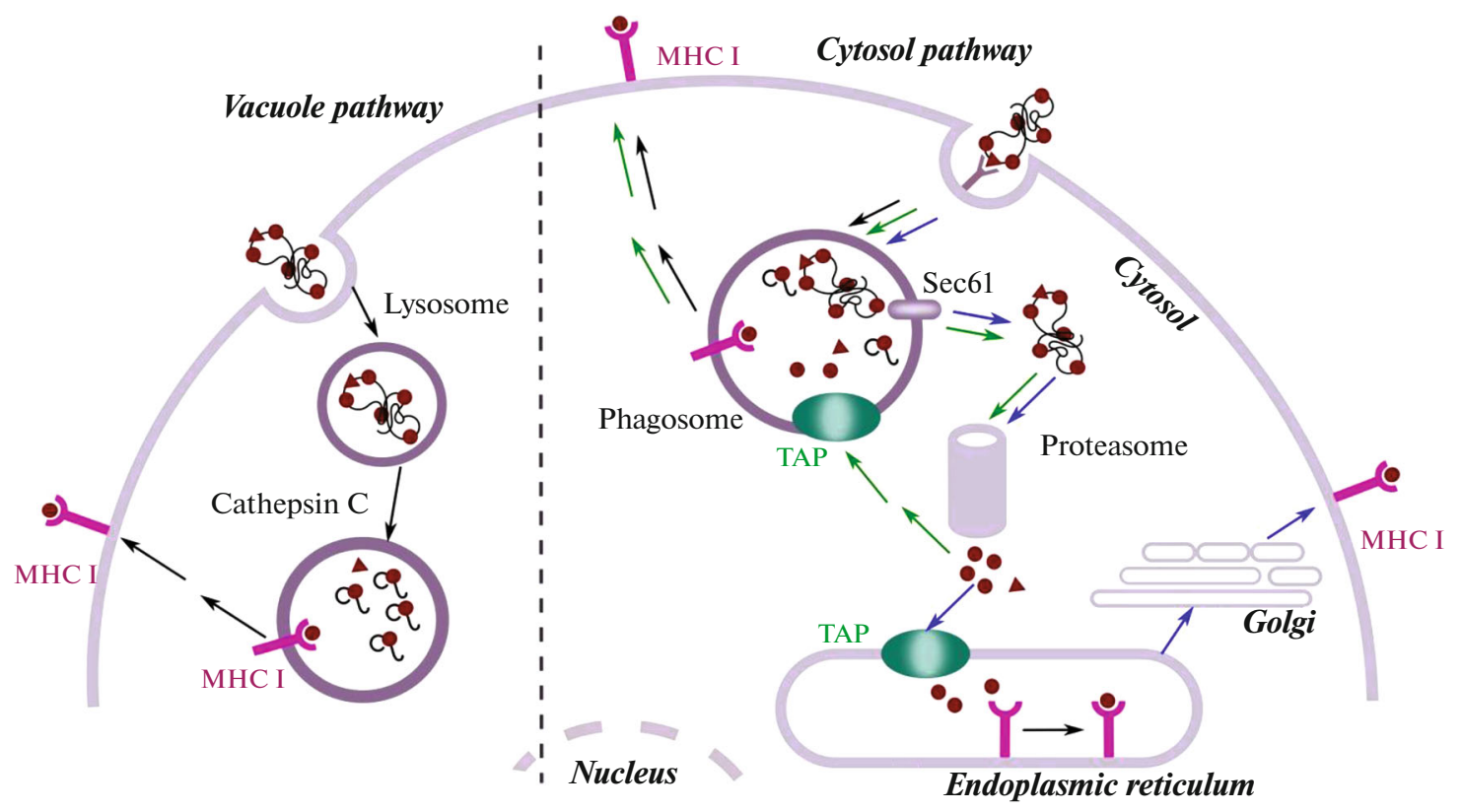

Fig. 2. Intracellular pathways of antigen cross-presentation.

membrane; they are involved in the transduction of external signals $[9,25]$. In addition, some lipids affect the curvature of the membrane, facilitating (in the case of positive curvature) the formation of the phagosome or, conversely, hindering (in the case of negative curvature) the process. They also recruit signaling proteins through interaction with specific lipid-binding domains and provide for electrostatic potential at the membrane surface to attract oppositely charged key signaling and effector proteins [23-25]. Intracellular vesicular traffic is regulated by controlled expression of lipids, whose role in the case of phagocytosis is to promote membrane fusion/separation. This, in turn, affects maturation of bactericidal phagolysosome and/or the pathway of antigen presentation on the surface of APCs [26].

Phosphoinositides are involved in the regulation of cytoskeleton reorganization at the early stages of phagocytosis with the participation of the actin-myosin system [23]. Other lipids such as arachidonic acid, ceramides, sphingosine, sphingomyelin, and sphingosine-1-phosphate (S1P), activate actin assembly and phagosome maturation [27]. Taking into account the role of certain lipids in the physiology of phagocytosis, a strategy was proposed to increase the effectiveness of innate immunity against bacterial infection by regulating the maturation of the phagosome using bioactive lipids. Thus, in in vitro experiments S1P and lysophosphatidic acid activated the phospholipase Dmediated response to mycobacteria dependent on the maturation of the phagolysosome in human macrophages $[28,29]$ and in type 2 alveolar epithelial cells [30]. For the targeted delivery of such lipids (secondary messengers), liposomes with an asymmetric distri- bution of phospholipids in the bilayer were developed. Their inner monolayer contained bioactive lipids that regulate the maturation of the phagosome, and the outer one contained phosphatidylserine (PS), which is characteristic of apoptotic bodies and presents the "eat me" signal to macrophages. Phosphatidic acid (PA) delivered this way enhanced the response to mycobacterial infection in macrophages and in bronchoalveolar lavage cells of tuberculosis patients and patients with multidrug-resistant bacterial pneumonia $[31,32]$. An in vitro model of cystic fibrosis employed macrophages with pharmacologically suppressed or mutant cystic fibrosis transmembrane regulator (CFTR), which are characterized by impaired maturation of the phagosome. Delivery of PA or PI (5) P (phosphatidylinositol-5-phosphate) to macrophages with impaired CFTR via such asymmetric bilayer liposomes induced response against Pseudomonas aeruginosa [32]. These results demonstrate the possibility of using liposomes for the delivery of bioactive lipids in order to enhance the antibacterial response by accelerating the maturation of phagosomes or restoring this process in the event of its disturbance by specific pathogens [32].

Cholesterol is often incorporated into liposomes to condense and stabilize the bilayer. In early studies when mice were intravenously immunized with liposomes prepared of various lipids functionalized at their polar heads and cholesterol, higher proportion of cholesterol enhanced humoral immune response, which was associated with greater stability of the liposomes in the bloodstream [33]. The effect of cholesterol on the adjuvant properties of liposomes is ambiguous and depends on a number of liposome characteristics. 
Thus, increase in the cholesterol content in small neutral monolamellar liposomes caused activation of the complement cascade to a lesser extent, while in large negatively charged multilamellar liposomes it enhanced complement activation [34]. In the case of leishmaniasis infection, liposomal delivery of cholesterol by a single intracardiac injection to infected hamsters has provided a strong protective therapeutic effect [35]. One of the factors weakening the host immune response to the invasion of protozoal parasites is the depletion of cholesterol in infected macrophages and subsequent impairment of antigen presentation due to a decrease in membrane viscosity. The same authors showed that liposomal cholesterol reactivates leishmania-infected macrophages and stimulates the innate immunity [36].

\section{LIPOSOMES AND ADAPTIVE IMMUNITY}

In contrast to the intrinsic property of liposomes to activate innate immunity, further induction of APCs for the secretion of cytokines that trigger differentiation of naive $\mathrm{T}$ lymphocytes into different subpopulations of CD4+ and/or CD8+ T cells depends on the physicochemical characteristics of liposomes: size; lipid composition, determining the phase state of the bilayer and liposome charge; and the presence of costimulatory molecules (immunostimulants/immunomodulators). Specifically designed liposomes carrying antigens can simultaneously activate different signal transduction pathways and elicit specific $\mathrm{T}$ - and/or $\mathrm{B}$-cell response. Antigens exposed on the surface of liposomes can stimulate B lymphocytes inducing humoral immune response, as well as induce T-cell responses. Encapsulated antigens, which require intracellular destruction of liposomes, are capable of inducing CTLs [9]. Data on the effect of the size and composition of liposomes on their immunogenicity are contradictory. In addition, since most liposomes are not able to spontaneously enter lymph nodes and can be transported therein only after internalization by peripheral APCs, the route of drug administration (subcutaneous, intradermal, intramuscular, intravenous, etc.) has a great influence on the type of immune response [37]. Thus, in each specific case, when developing a liposomal vaccine, it is necessary to conduct a special study.

\section{Effect of Particle Size}

Size of liposomes can affect the rate at which they are cleared from the injection site and, therefore, kinetics of their accumulation in lymph nodes. The size should be small enough for the liposomes to migrate through interstitial tissue channels. For example, a significantly greater part of large liposomes was retained at the injection site upon subcutaneous immunization, independently of the composition of the liquid-phase lipid bilayer: egg phosphatidylcho- line-egg phosphatidylglycerol-cholesterol (ePCePG-Chol, 10: 1: 4; average sizes 40, 70, 170, $400 \mathrm{~nm}$ and larger) [38] or ePC-dioleoylphosphatidylethanolamine-dioleoyltrimethylammonium propane (ePC-DOPE-DOTAP, $8: 4: 2$; average sizes 140 and $560 \mathrm{~nm}$, polydispersity index, PDI, 0.15 and 0.6 , respectively) [39]. However, there was no difference between the accumulation of liposomes in the draining lymph nodes within $52 \mathrm{~h} \mathrm{[38]} \mathrm{or} 8$ days [39] after the injection. The authors of [38] suggested that this is due to more efficient retention of large liposomes in the lymph nodes, compared to smaller liposomes, which migrate further into the bloodstream. The results of these studies are ambiguous since the influence of the composition and charge of liposomes was not taken into account. In addition, liposomal dispersions were heterogeneous in size, and the indicated values are average over the distribution, that is, the samples contain a sufficient number of particles of larger and smaller sizes.

Large liposomes $(>500 \mathrm{~nm})$ are predominantly taken up by macrophages through macropinocytosis, while smaller liposomes migrate to the lymph nodes by passive transport and are captured by DCs. In both cases, strong immune response can be induced [40]. Accordingly, the size of liposomes can determine its type: for small liposomes, stimulation of $\mathrm{T}_{\mathrm{H}} 1$ cells is more characteristic, and for large liposomes, $\mathrm{T}_{\mathrm{H}} 2$ cells are stimulated. It is believed that a mixture of particles of different sizes is optimal to obtain a strong immune response (review [41] and references therein). The prerequisites for different presentation of antigen depending on the size of the vesicles were also observed upon internalization by phagocytes: the antigen encapsulated in large $(560 \mathrm{~nm})$ vesicles was localized in early immature phagosomes, where capture by MHC class II molecules prevails for subsequent presentation to CD4+ T cells, while the antigen in small $(155 \mathrm{~nm})$ liposomes quickly entered late endosomes/lysosomes, which reduced the efficiency of its restriction by MHC class II molecules [42]. However, experimental data on the relationship between the size of liposomes and the type of immune response are contradictory. In addition, since large liposomes are able to retain antigen at the injection site, they maintain its concentration, allowing for a gradual release (depot effect). For example, when studying the relationship between the size of liposomes and the efficiency of stimulating the humoral immune response, mice were immunized intranasally with cationic monolamellar liposomes of 70, 140, and $400 \mathrm{~nm}$ in size and multilamellar giant (not extruded) liposomes [43]; the highest titers of class $\mathrm{G}$ immunoglobulins (IgG) were stimulated by the smallest monolamellar liposomes and giant multilamellar liposomes. The authors believe that multilamellar liposomes can stimulate a strong immune response due to more reliable protection of the antigen from degradation in the multilayer structure. 
A number of studies have shown the dependence of the type of immune response- $\mathrm{T}_{\mathrm{H}} 1$ or $\mathrm{T}_{\mathrm{H}} 2$-on the size of liposomes [44, 45]. For example, when ovalbumin (OVA) was included as a model antigen in liposomes $\geq 225 \mathrm{~nm}$ in size (1-monopalmitoylglycerolcholesterol-dicetyl phosphate, $5: 4: 1$ ), subcutaneous vaccination stimulated a strong $\mathrm{T}_{\mathrm{H}} 1$ response in mice, judging by the level of IFN- $\gamma$ and high titer of serum IgG2a. At the same time, the same antigen encapsulated in smaller liposomes $(\leq 155 \mathrm{~nm})$ induced a response predominantly along the $\mathrm{T}_{\mathrm{H}} 2$-activation pathway, as evidenced by the level of IgG1 and an increase in IL-5 production in the lymph nodes [45]. Similarly, dipalmitoylphosphatidylcholine-cholesterol (DPPC-Chol, $2: 1$ ) liposomes $\geq 400 \mathrm{~nm}$ (up to $1100 \mathrm{~nm}$ ) induced a stronger $\mathrm{T}_{\mathrm{H}} 1$ response than liposomes with an average size of $120 \mathrm{~nm}$ upon subcutaneous immunization with the encapsulated major surface glycoprotein of Leishmania rgp63 [46]. This effect of liposome size is associated with differences in particle traffic to lymph nodes: small particles (20$200 \mathrm{~nm}$ ) freely migrate to draining lymph nodes, where they are captured by resident DCs, while large vesicles (more than $500 \mathrm{~nm}$ ) are internalized by tissuespecific DCs [47].

However, in the case of cationic liposomes with a bilayer in the gel phase (the composition of dioctadecyl dimethylammonium bromide-trehalose-6,6'dibehenate, DDA-TDB, was commercially named CAF01; TDB is a synthetic glycolipid analogue of the cord factor of mycobacteria activating macrophages and DCs), no difference was found between liposomes with average sizes of 200, 700, 1500, and $2500 \mathrm{~nm}$ when comparing the effect on the immune response they induced. All drugs were injected intramuscularly and stimulated the $T_{H} 1$ response [48]. Perhaps this is due to the positive surface charge, which allows even small liposomes to form a depot at the injection site due to interaction, for example, with negatively charged interstitial proteins.

\section{Effect of Liposome Composition}

The lipid composition of the bilayer determines the phase state of the liposome membrane, which, in turn, significantly affects the processes of fusion with plasma membrane and membranes of organelles of APCs and, consequently, the way of presentation of the antigen being delivered. Liposomes made of lipids in liquid disordered phase (Ld) facilitate cross-presentation of antigens by MHC class I molecules to a greater extent than liposomes with lipids in solid ordered phase (So) [49]. At the same time, in in vivo experiments, cationic solid-phase liposomes based on DDA induced a 100-fold stronger response of $T_{H} 1$ cells, as compared to liquid-phase liposomes from dioleoyl dimethylammonium bromide [50]. A solidphase cationic adjuvant CAF01 (see above), when administered in combination with a subunit vaccine against Mycobacterium tuberculosis (Mtb), caused a stable antigen-specific combined $T_{H} 1 / T_{H} 17$ response and partial protection against the Mtb infection [51]. Also, in an early work [52], it was shown that macrophages efficiently processed various protein antigens (OVA, bovine hemoglobin, or mouse hemoglobin) encapsulated in liquid-phase liposomes, either sensitive or insensitive to the medium $\mathrm{pH}$ (DOPE-palmitoyl homocysteine or dioleoylphosphatidylcholine (DOPC)-dioleoylphosphatidylserine, respectively) and presented antigen peptides with MHC class II molecules.

The lipid composition of the bilayer also determines the charge of the liposome surface, which can drastically affect the adjuvant properties. As a rule, positively charged liposomes are absorbed by APCs to a much greater extent than negatively charged or neutral ones [53, 54]. Cationic liposomes can interact with negatively charged mucosal surfaces, which prolongs the antigen exposure time (depot effect) and enhances endocytosis by antigen-presenting cells and cell-mediated immune response [10, 53-56] compared to neutral liposomes, which typically induce antibodies [57]. After intramuscular immunization, nearly neutral liposomes made of distearoylphosphatidylcholine (DSPC)-TDB (zeta potential $-8 \mathrm{mV}$ ) entered the lymph much faster than cationic liposomes made of CAF01 (zeta potential $+50 \mathrm{mV}$ ) despite their large size (1620 vs $475 \mathrm{~nm}$, respectively) [54]. Moreover, only the CAF01 liposomes elicited cellular immune response, judging by the expression of IFN- $\gamma$ and IL-17 by activated T cells, which could also be facilitated by the induction of proinflammatory microenvironment at the injection site under the action of DDA accompanied by an influx of APCs [54, 58]. Another example comes from veterinary medicine: cationic DPPC-dioleoyl trimethylammonium propane (DOTAP) liposomes, when used as an adjuvant with live-attenuated vaccine, significantly increased the production of antibodies against infectious bursitis (Gumboro disease) in chickens with minimal damage to the bursal region [59].

Anionic liposomes can also modulate the immune response. As mentioned above, PS presented on the surface of apoptotic bodies is a signal for attack by macrophages and DCs expressing PS receptors. After internalization of apoptotic bodies, phagocytes become immunotolerant [60]. However, if recognition occurs in the presence of certain PAMPs (see further sections on co-stimulatory components of vaccines), cytokine profile of the $T_{\mathrm{H}} 17$ lymphocyte subpopulation is produced [47], and the presentation of antigens restricted by MHC molecules of class I and class II is equally efficient [61]. In another example anionic liposomes containing phosphatidylglycerol (PG) loaded with a peptide antigen evoked a strong specific response of regulatory $\mathrm{T}$ lymphocytes (Tregs) [62]. 
The vital role of Tregs is to control the degree and duration of the immune response through the regulation of the function of effector $T$ lymphocytes $\left(T_{H}\right.$ cells and CTLs); Treg dysfunction is often associated with autoimmune diseases. When the rigidity of the PCPG-(Chol) $(4: 1(: 2))$ liposome bilayer was altered by varying the acyl chain length and degree of saturation or percent of cholesterol, bilayer rigidity positively correlated with the response of Tregs, as was shown in vitro in mouse bone marrow-derived DCs and in mice in vivo [63].

\section{Effect of Immunostimulatory Molecules (PRR Ligands)}

The adjuvant properties of liposomes can be enhanced or directed towards one or another type of immune response using specific ligands that activate certain receptors on APCs. The discovery of receptors that recognize PAMPs (PRRs) had a huge impact on the development of vaccinology $[64,65]$. A wide variety of molecule classes can act as specific ligands of PRRs: DNA, RNA, lipids, carbohydrates, proteins, peptides, and low molecular weight substances. PRRs include TLRs, nucleotide-binding oligomerization domain receptors (NOD) receptors, NOD-like receptors (NLRs), retinoic acid-inducible gene (RIG)-like helicases (RLHs) [66], and C-type lectin receptors (CLRs) [67]. Activation of these receptors plays a key role in DC maturation and cytokine production. PRRs are located in various cellular compartments: on the surface of the plasma membrane (e.g. TLR-1, -2, $-4,-5,-6$, CLRs), in endosomes (TLR3, -7, -8, -9), or cytoplasm (NLRs, RLHs) [66-68]. Localization of the receptors reflects localization of corresponding PAMPs. Thus, ligands of cell surface PRRs are expressed on the surface of pathogens, while ligands of endosomal PRRs are found inside cells, for example, nucleotides [67, 69]. Activation of PRRs typically induces pro-inflammatory responses and/or production of type I interferons. However, different PRRs induce different signaling pathways and thus modulate the immune response pathway $[67,70]$.

Direction the type of immune response via one or another pathway may correspond to the origin of the PAMP. For example, PRRs that recognize bacterial ligands often trigger the $T_{H} 1$ response, which effectively fights certain microbial infections [71]. Similarly, double-stranded viral RNA activates CTLs that can suppress viral infection [72]. In bacterial DNA, unmethylated cytosine-guanine motifs are much more common than in eukaryotic chromosomes; therefore, synthetic oligodeoxyribonucleotides containing the $\mathrm{CpG}$ motifs (CpG-ODN) represent PAMPs and exhibit immunostimulatory activity. CpG motifs are recognized by the TLR9 receptor, which is expressed in the membranes of endosomal compartments of many immunocompetent cells, including B cells, monocytes, NK, DCs, and macrophages [73]. As a result, the production of pro-inflammatory cyto- kines (TNF- $\alpha$, IL-1, IL-6, IL-12, IFN- $\alpha$, etc.), chemokines (MIP-2, MCP-1, RANTES, IP-10, etc.), MHC class II molecules, and co-stimulatory molecules (CD40, CD80, CD83, CD86) is stimulated [74]. In an early work [75], immunization of mice with a mixture of $\mathrm{CpG}-\mathrm{ODN}$ and liposomes (PC-PGChol, $2: 0.2: 1)$ encapsulating the MHC class Irestricted OVA and gp33 peptide epitopes activated maturation of DCs, promoted cross-presentation, and induction of an immune response along the $T_{H} 1$ pathway. Synthetic CpG ODNs are successfully used in the design of liposomal vaccines. The immunostimulant can be co-encapsulated in the internal aqueous volume of liposomes or adsorbed on surface of cationic liposomes [74, 76, 77]. Recently, a new platform for the development of vaccines has been proposed: a covalent conjugate of $\mathrm{CpG}-\mathrm{ODN}$ with a conserved Streptococcus agalactiae (a group B streptococcus) pili protein was adsorbed onto cationic liposomes. Compared to immunization with a simple mixture of $\mathrm{CpG}$ ODN and the liposomes with an associated protein, intramuscular administration of the whole construct promoted the formation of a depot at the injection site and stimulated a multi-stage versatile immune response [77].

Among TLRs studied in terms of their influence on the immune response, the most significant are TLR3, TLR7, TRL9, and TLR4 [2]. The latter one is localized on the surface of APCs and, therefore, is more accessible, in contrast to endosomal TLR3, TLR7, and TRL9. Delivery systems based on nanoparticles, including liposomes, are able to provide efficient internalization required for the access to the intracellular receptors. For example, immunization with (neutral) liposomes loaded with CpG-ODN together with an antigen (tetanus toxoid) yielded a high titer of protective antibodies; this response was not observed when liposomes with the antigen lacking CpG-ODN were used [78]. In a model of transgenic mice expressing hepatitis B virus, a complex of cationic liposomes with a CpG-ODN associated with hepatitis B surface antigen ( $\mathrm{HBsAg}$ ) induced $\mathrm{T}$ - and $\mathrm{B}$-cell immune responses, while $\mathrm{HBsAg}$ alone caused only B-cell response [79]. Also, when lipophilic derivatives of muramyl dipeptide (MDP, recognized by intracellular NOD2-like receptors), conjugates with phosphatidylethanolamine and dipalmitoylglycerol, were added to the liposomes with the $\mathrm{HBsAg}$ antigen, antibody titers and levels of IFN- $\gamma$ production (the $T_{H} 1$ response) increased compared with compositions lacking the MDP analogues [80]. Single-stranded RNAs (TLR7 ligands) encapsulated in liposomes with antigens mediated strong cellular responses during immunization of mice [81]. The synthetic analogue of doublestranded RNA polyinosinic acid-polycytidylic acid (poly(I : C), TLR3 ligand) enhanced cross-presentation [82] and, when complexed with cationic liposomes, promoted the induction of CTLs [83]. Moreover, the combination of an antigen and a ligand of 


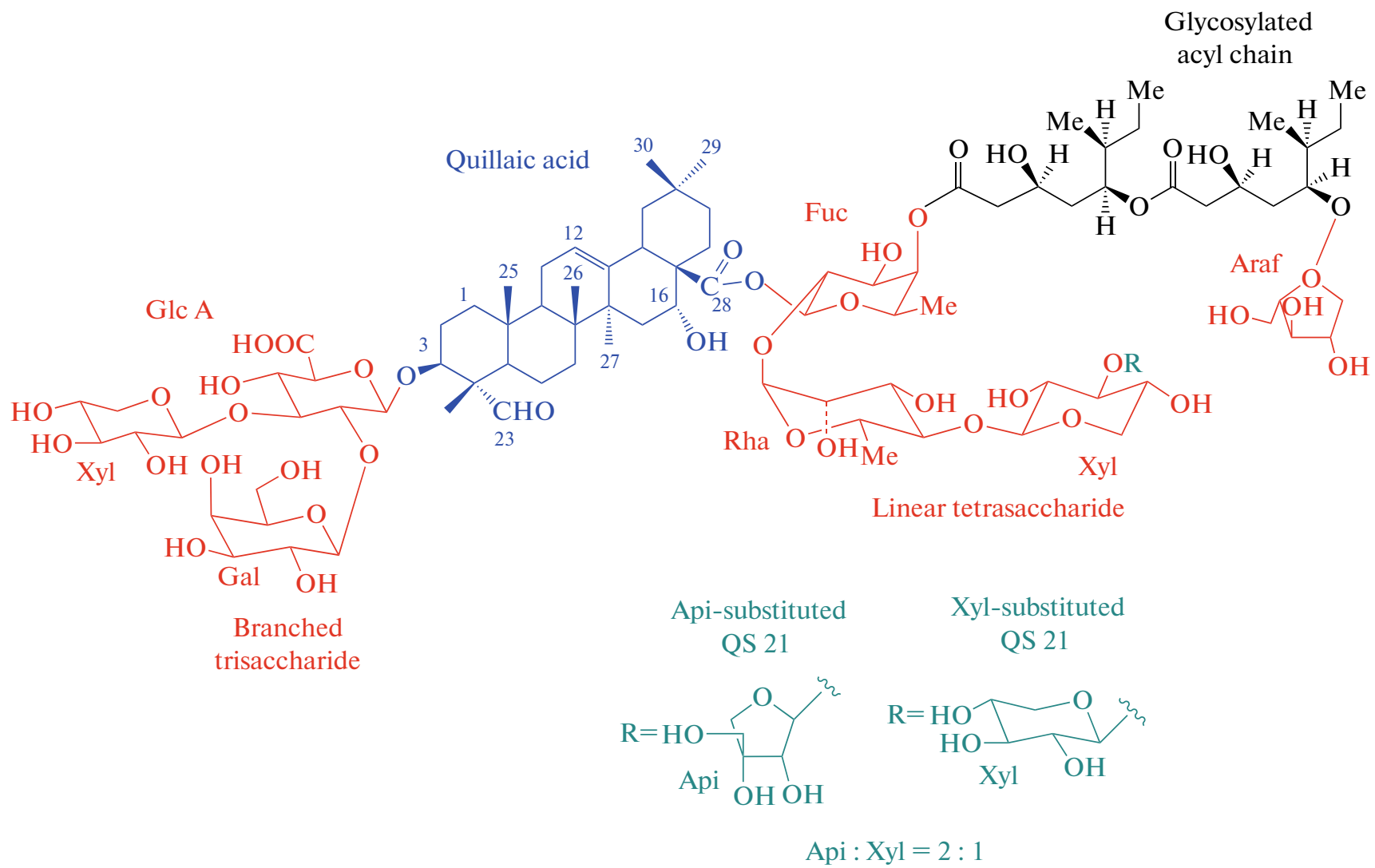

Fig. 3. Structure of QS-21, a triterpene glycoside from Quillaja saponaria (adapted from [88]). Glc A, $\beta$-glucuronylpyranosyl; Glc, $\beta$ - $D$-glucopyranosyl; Gal, $\beta$ - $D$-galactopyranosyl; Xyl, $\beta$ - $D$-xylopyranosyl; Fuc, $\beta$ - $D$-fucopyranosyl; Api, $\beta$ - $D$-apiofuranosyl; Rha, $\alpha$ - $L$-rhamnopyranosyl; Araf, $\alpha$ - $L$-arabinofuranosyl.

intracellular receptors in a single complex made it possible to significantly enhance the immune response, in contrast to the use of a simple mixture of these components. Obviously, immobilization of a PRR ligand (immunostimulant) on surface of the adjuvant carrier (liposome) should also contribute to more efficient stimulation of APCs.

Monophosphoryl lipid A (MPLA, detoxified fraction of endotoxin lipid A; a TLR4 ligand) is a safe and effective liposomal adjuvant that has been used in combination with many candidate antigens in the development of new vaccines to combat malaria, HIV1 , and other infections (as well as a number of oncological diseases) [84, 85]. For example, the RTS.S antigen (hepatitis B virion expressing epitopes of the main surface protein circumsporozoite (CS) of the $P$. falciparum malaria plasmodium) caused CTL response and a dose-dependent increase in the titer of specific IgG when incorporated into liposomes with MPLA in vivo; without MPLA, the liposomal form was ineffective [86]. At the sporozoite stage, the P. falciparum plasmodium is coated with the CS protein that ensures the invasion into hepatocytes. The first highly protective recombinant vaccine against malaria was the RTS.S complex with MPLA and QS-21, a tri- terpene glycoside from the Quillaja saponaria tree [87, 88] (Fig. 3). Unlike MPLA, the mechanism of action of QS-21 is not fully understood. This saponin is known for its hemolytic activity, which is suppressed when incorporated into liposomes with cholesterol (as in the AS01 complex). Recently, QS-21 was shown to activate a specific signaling pathway in monocytes (formation of the ASC-NLRP3 inflammasome, a multi-protein complex that causes the release of interleukins IL-1 $\beta /$ IL-18 [89]), but the role of this pathway in the body is still unclear. Also, it has been shown that genetically engineered soluble CS protein (FMP013) of $P$. falciparum can induce lifelong sterilizing immunity when administered in a liposomal form containing a synthetic MPLA analog 3D-PHAD ${ }^{\circledR}$ and a QS21 saponin (ALFQ, Army Liposomal Formulation adjuvant) [90-92]. The vaccine is currently at phase I clinical trials [93]. The $78 \mathrm{kDa}$ Leishmania donovani antigen encapsulated in liposomes in combination with MPLA is another example. It induced the $T_{H} 1$ pathway response and reduced the parasitic load in immunized mice after infection [94].

Variation of immunostimulants allows the modulation of the type of immune response to the same antigen. For example, immunization of mice with 
liposomes containing OVA and $\mathrm{CpG}-\mathrm{ODN}$ elicited the $\mathrm{T}_{\mathrm{H}} 1$-type response with the production of IFN- $\gamma$ and $\mathrm{IgG2a}$, while the same antigen in liposomes with Pam3CSK4 (PAM is a synthetic lipopeptide consisting of tripalmitoyl-S-glyceryl cysteine conjugated to the SKKKK pentapeptide; it is a ligand of TLR2 localized on the surface of APCs) induced the secretion of $\operatorname{IgG} 1$, which corresponds to the response along the $\mathrm{T}_{\mathrm{H}} 2$ pathway $[95,96]$.

The CAF09 adjuvant inducing the CD8+ T-cell response consists of cationic DDA liposomes stabilized by monomycoloyl-1-glycerol (a synthetic analog of mycobacterial cell wall lipid, a potent stimulator of human DCs) and a TLR3 ligand poly(I : C) [97, 98]. CAF09 showed high rate of antigen-specific CTLs against model OVA antigen, as well as against the Mtb (TB10.3, H56), HIV (Gag p24), and human papillomavirus HPV (E7) antigens, when tested in mice [97, 98]. In a mouse model of TC- 1 skin tumor (subcutaneous inoculation of HPV-16 expressing E-7), immunization with the E-7 antigen with CAF09 adjuvant significantly inhibited tumor growth [97].

\section{LIPOSOMAL VACCINES CARRYING THE ANTIGEN-LIPID CONJUGATES}

Encapsulation of antigens in the internal aqueous volume of liposomes is often accompanied by low loading efficiency and losses during vaccine production and purification. On the other hand, antigens adsorbed on the surface (this method is usually used in the case of cationic liposomes) can be rapidly desorbed under physiological conditions. The incorporation of antigens, particularly peptides, in the form of lipid conjugates with into the liposome membrane solves these problems. In recent years, interest in liposome-based peptide vaccines has grown $[41,43,74$, 99]. This is due to (1) the development of powerful bioinformatics resources, which can significantly reduce the time and labor costs for the search for new epitopes of biological targets, and (2) improvement of technologies for solid-phase chemical synthesis of peptides. Here are the examples of work of several groups of researchers.

The authors of [100] conjugated nonameric T-cell epitopes of coronavirus SARS-CoV with the surface of functionalized liquid-phase anionic liposomes prepared of DOPC-Chol-dioleoylphosphatidylglycerol-DOPE disuccinimidyl suberate mixture at a molar ratio of $\sim 6: 7: 2: 1$. Four CTL epitopes of the viral nucleocapsid, restricted by HLA-A*0201 (human leukocyte antigen serotype, one of the MHC class I alleles; the HLA-A*02 group of alleles is widespread in the world) were identified experimentally using transgenic mice and recombinant adenovirus expressing eight epitopes predicted in silico. Upon subcutaneous immunization, two liposomal peptides in combination with $\mathrm{CpG}-\mathrm{ODN}$ induced specific T-cell response; one of these vaccines caused clearance of the vaccinia virus, expressing SARS-CoV epitopes, in mice [100]. The same authors [101] used a similar approach to construct peptide vaccines with CTL epitopes of SARS-CoV polyprotein 1a (the largest conserved protein of the virus, 4382 aa; precursor of non-structural proteins). Of the 30 peptides predicted by immunoinformatics methods, eight induced significant CTL response and were conjugated to liposomes. Of these, seven showed activity against the virus in vivo, and one variant of the vaccine induced the formation of memory cells [101].

Toth et al. developed a different approach to the preparation of immunogenic peptide-lipid conjugates [41]. They proposed to construct a "lipid-based peptide" system: a molecule built of lipoamino acids with a branching module for modification by several peptide epitopes (Fig. 4) [102]. Using solid-phase peptide synthesis, conjugates with epitopes of various pathogens, including parasitic ones (chlamydia, helminths) and group A streptococci, were obtained [103]. Such systems form nanoparticles in aqueous media and have shown the ability to induce an antibody-mediated immune response without additional administration of an adjuvant. When the conjugates were included in liposomes, the humoral response increased: a lipopeptide containing a B-cell epitope and a T-helper epitope of group A streptococci in DPPC-DDA-Chol liposomes induced higher titers of $\mathrm{IgG}$ and IgA upon immunization of mice compared to the conjugate administered outside the liposomes [104].

Another method for immobilization of peptide antigens on the surface of liposomes is based on the complementary interaction of heterodimeric peptide pairs containing lysine (PepK) and glutamic acid (pepE) residues and forming a coiled-coil structure $[105,106]$. PepK was conjugated with cholesterol (PepK-Chol) and incorporated into the bilayer of cationic liposomes, to which the pepE conjugate with the model antigen OVA323 was efficiently bound (dissociation constant $K_{\mathrm{d}}=166 \mathrm{nM}$ ). Colocalization of antigen and liposomes with PepK-Chol in vivo increased from 35 to $80 \%$ compared to non-functionalized liposomes; proliferation of CD4+ T cells in vitro increased 5 times; immunization of mice induced a stronger response (increased production of IFN- $\gamma$ and IL-10) by these cells [106].

An interesting (and unexpected) way of binding antigens to liposomes is based on complexation between the polyhistidine fragment (His-tag) of recombinant proteins or peptides and a phospholipid modified at the terminal carbon of the acyl residue at the $s n-2$ position with a porphyrin-chelated cobalt (Co-PoPC) [107] (Fig. 5). Interaction of the His-tag with the porphyrin group upon immersion in the lipid bilayer is accompanied by the $\mathrm{Co}(\mathrm{II}) \rightarrow \mathrm{Co}$ (III) transition; a rather strong complex is formed inside the 


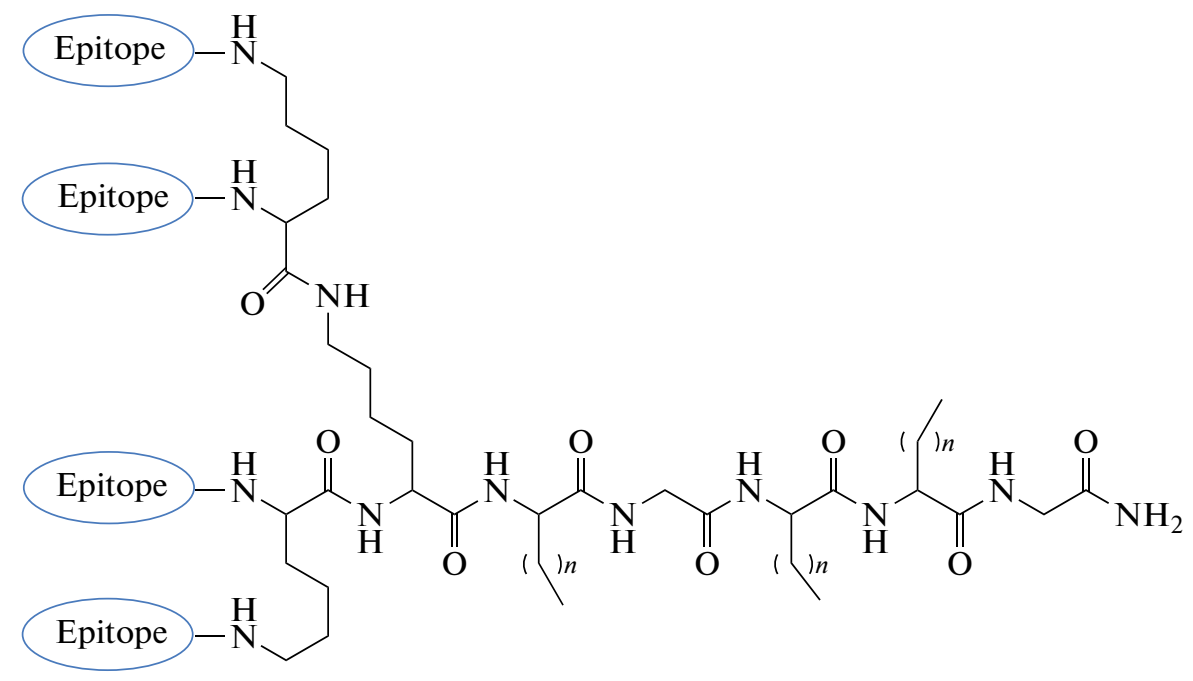

Fig. 4. Conjugate of lipoamino acids with a branching module for modification with several peptide epitopes [102].

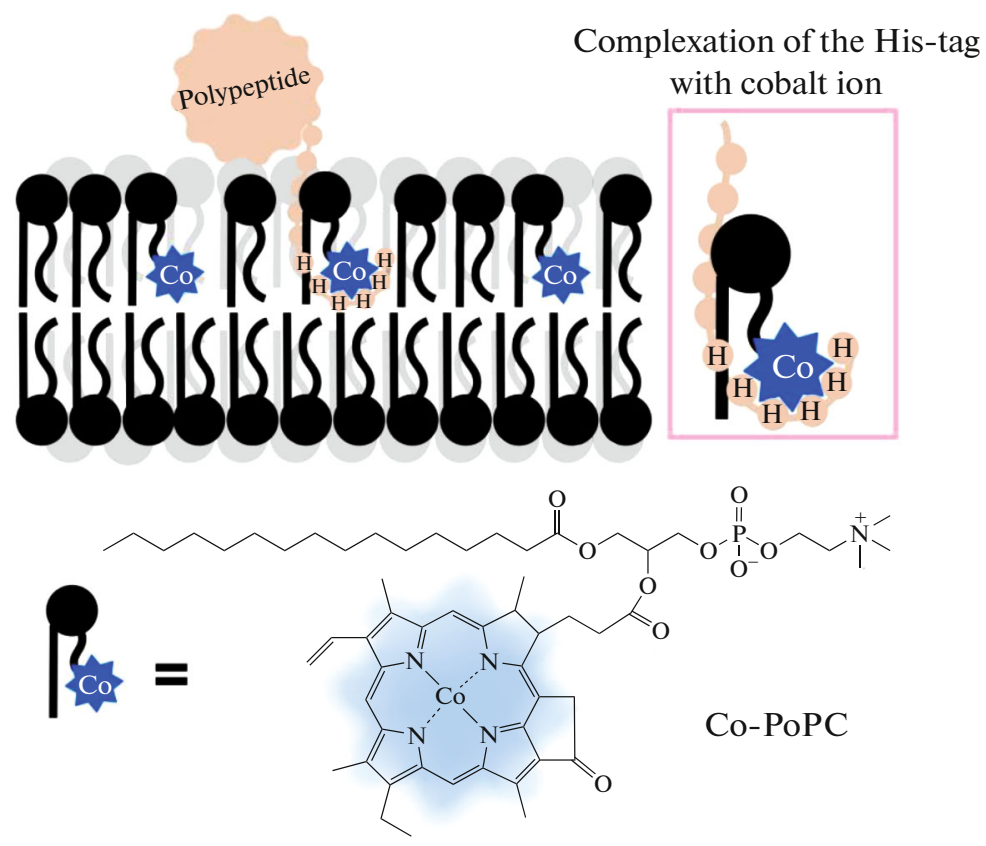

Fig. 5. Incorporation of a His-tag polypeptide into a monolayer of lipid bilayer carrying Co-PoPC. Imidazole groups of histidine residues are coordinated by cobalt in the hydrophobic phase of the bilayer [107].

hydrophobic region of the bilayer, which irreversibly retains the protein (peptide) in the blood serum and in a competitive environment with excess $\left(10^{6}\right)$ imidazole. Liposomes carrying thus-grafted fragment of the HIV envelope protein gp41, upon immunization of mice, caused the production of specific antibodies [107].

The authors proposed the same approach to the development of a transmission-blocking vaccine (TBV) by immunizing a mosquito during bloodsucking (the development of the parasite is blocked in the insect's intestines) [108]. The creation of TBV is one of the most important directions being developed by WHO in the fight against malaria. The Pfs 25 P. falciparum plasmodium protein $(25 \mathrm{kDa}, 11$ disulfide bonds) is a good candidate antigen for TBV [109], but, for example, with the aluminum adjuvant, Pfs 25 has not shown sufficient immunogenicity in clinical trials [110]. In [108], liposomes of DPPC-Chol-PHAD (synthetic analogue of MPLA, phosphorylated hexaacyl disaccharide-Co-PoPC, $4: 2: 1: 1$, were incubated with recombinant His-tag-Pfs 25 before immu- 
nization and then injected intramuscularly in mice and rabbits, together with an adjuvant QS-21; stable antigen-liposome complexes were transported to the lymph nodes, which facilitated the efficient uptake by APCs, the generation of long-lived antigen-specific plasma cells, and a much more intensive production of functional antibodies (orders of magnitude higher), compared to other adjuvant drugs, which are obtained by mixing the components before immunization. Liposomes containing lipids with a nickel nitrilotriacetate (Ni-NTA) complex in the head group are unable to retain His-tag ligands in biological media [111] (which has also been shown for Co-NTA liposomal complexes [107]). The same authors demonstrated the effectiveness of the Co-PoPC/PHAD liposomal platform in production of an antimalarial vaccine based on another candidate TBV antigen, the His-tagged fragment of the Pfs 230 protein (a.a. 443-731), which is expressed on the surface of the $P$. falciparum gametocyte in human erythrocytes [112]. Finally, this platform, applied to the receptor binding domain (RBD) of the SARS-CoV-2 virus spike protein, made it possible to produce high titers of antibodies during immunization of mice (by blocking the interaction with the angiotensin converting enzyme 2 (ACE2) receptor and inhibiting viral replication), and the addition of QS-21 to the preparation increased the specific polyfunctional T-cell response [113].

\section{LIPOSOMES AS ADJUVANTS FOR PREVENTION AND TREATMENT OF INFECTIOUS DISEASES IN CLINICS}

Sufficiently structured reviews of liposomal vaccines, both studied in laboratories and used in the clinic for the prevention of serious viral, bacterial, fungal, and parasitic infections, including tuberculosis, have been published recently [9, 10, 114-116]. To date, several prophylactic vaccines based on adjuvant lipid complexes-liposomes and lipid nanoparticleshave been licensed on the pharmaceutical market. A number of clinical trials go through various stages, a few examples are given in Table 1. Epaxal® [117] and Inflexal ${ }^{\circledR}$ are injected intramuscularly to protect against hepatitis $\mathrm{A}$ and seasonal influenza, respectively (and Inflexal ${ }^{\circledR}$ is a trivalent vaccine) $[118,119]$. In 2000, the EEC approved the Nasalflu ${ }^{\circledR}$ liposomebased influenza vaccine in the form of an intranasal spray, but a year later it was withdrawn from use due to cases of facial nerve paralysis (Bell's palsy) [120]. Epaxal ${ }^{\circledR}$ and Inflexal ${ }^{\circledR}$ are dispersions of ready for use liposomes that carry antigens adsorbed on the surface. Mosquirix ${ }^{\circledR}$ malaria vaccine $[86,121]$ and Shringrix ${ }^{\circledR}$ herpes zoster vaccines are prepared by mixing liposomes containing appropriate immunostimulants with the antigens. The Shringrix ${ }^{\circledR}$ vaccine demonstrates not only a high safety profile, but also a stronger protective effect compared to traditional vaccines based on whole pathogens (at least 4 years of protection against relapse, even among patients over 70 years old) [122, 123]. Obviously, this result is explained by the vaccine rational design: the correct choice of the antigen, because the gE envelope glycoprotein plays a decisive role in the replication of the virus and its intercellular transmission; QS-21 guarantees the activation of the innate immune response, and liposomal MPLA, through TLR4, activates the $T_{H} 1$ pathway; as a result, a strong cellular immunity develops. Liposome stability is also an important factor $[115,124,125]$.

In 2020, against the background of the SARS$\mathrm{CoV}-2$ virus pandemic, the first vaccines based on lipid nanoparticles and mRNA of the full-size S-protein of the virus spike (Pfizer/BioNTech and Moderna) were rapidly introduced into the clinic. Importantly, nanosized liposomes can be quite classified as a generation of lipid nanoparticles [129]. In this case, the role of lipid molecules is to ensure the compaction of long-chain nucleic acid molecules, protect it from degradation under the action of extracellular enzymes, and provide for the transport of the nanoparticle into the cell due to endocytosis (phagocytosis or pinocytosis) and subsequent release of mRNA from the endosome (phagosome) into the cytoplasm for translation and expression of a protein with immunogenic epitopes. Presumably, the release of mRNA from the endosome into the cytoplasm occurs due to the transition of the LNP lipids during acidification into the cationic form, which contributes to their contact with anionic lipids of the periplasmic monolayer of the endosome membrane, formation of non-bilayer structures, and membrane destabilization [130]. Due to such a variety of requirements for the organization of LNP bearing an mRNA, the lipid platform must include several classes of lipids. The structures of ionizable (cationic) lipids, which ensure the compaction of mRNA molecules, are very similar in vaccines from both manufacturers (Fig. 6) [131].

The exact structural organization of mRNA-LNP is not known, but based on NMR spectroscopy data, the most probable model is the "amorphous coreshell" model, which is similar to the packing of small interference RNAs (siRNAs) in LNPs, where RNA is located either in water pores inside inverted micelles of cationic lipids (Fig. 7a), or in small water "pockets" between lipids homogeneously dispersed in the lipid core (Fig. 7b) [132]. The second option is more consistent with the experimental data [131].

At the same time, according to the data of studies using cryo-EM, 4000 nucleotides long mRNA packed in LNPs (approximately equal to the size of mRNA in Pfizer/BioNTech and Moderna vaccines) can be predominantly localized in relatively large water blebs [133]. The asymmetry of the mRNA-LNP structure is quite understandable: mRNA molecules are hundreds of times larger than siRNA molecules. 


\begin{tabular}{|c|c|c|c|c|c|c|c|c|c|c|c|c|c|}
\hline 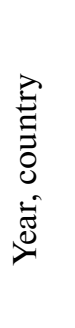 & 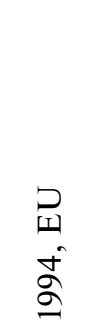 & $\begin{array}{l}\text { 미 } \\
\hat{a} \\
\text { ลू }\end{array}$ & 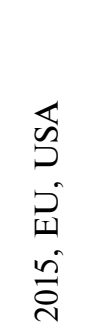 & 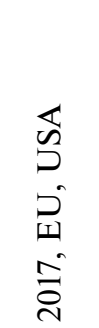 & 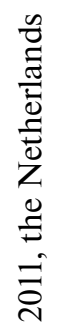 & 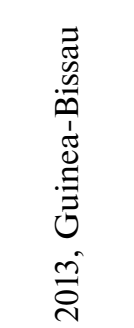 & 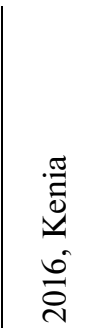 & 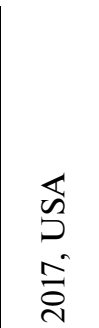 & 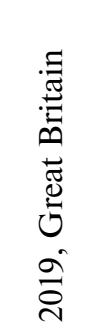 & 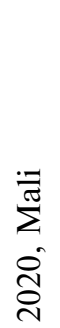 & 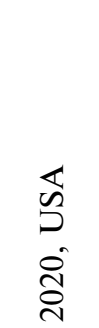 & 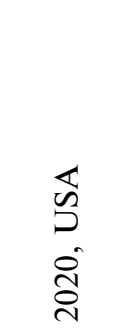 & 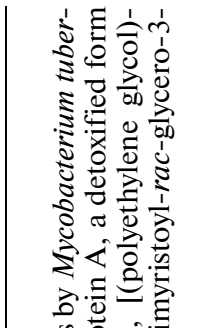 \\
\hline 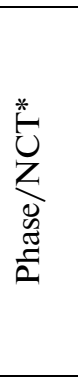 & 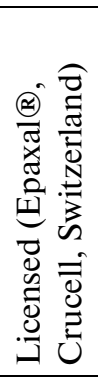 & 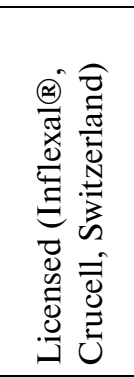 & 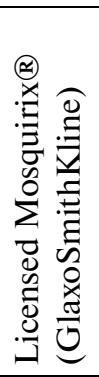 & 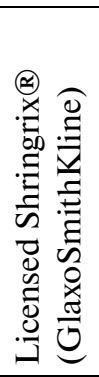 & 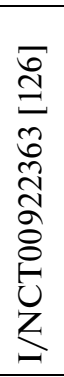 & 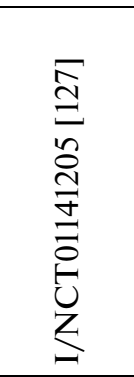 & 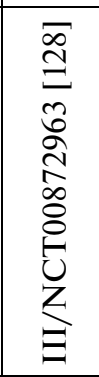 & 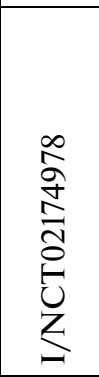 & 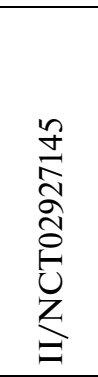 & 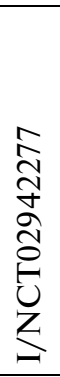 & 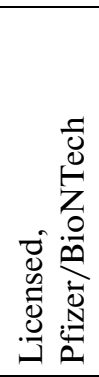 & 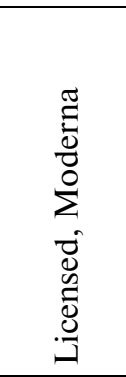 & 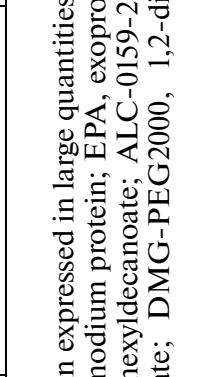 \\
\hline 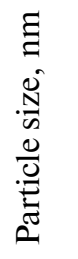 & $\frac{n}{i}$ & $\frac{n}{i}$ & & $\begin{array}{l}8 \\
1 \\
1 \\
\text { in }\end{array}$ & 1 & I & 1 & 1 & 1 & 1 & $\begin{array}{l}8 \\
1 \\
8 \\
8\end{array}$ & $\begin{array}{l}8 \\
1 \\
8 \\
8\end{array}$ & 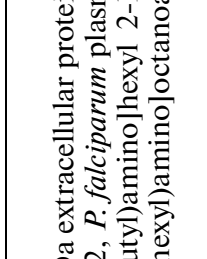 \\
\hline 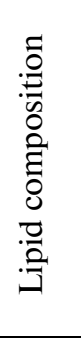 & 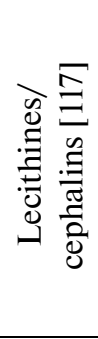 & 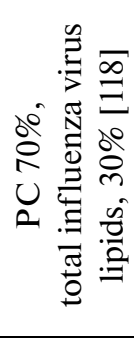 & $\begin{array}{l}\bar{\Xi} \\
\bar{\Xi} \\
\text { U } \\
0 \\
0 \\
0\end{array}$ & $\begin{array}{l}\overline{0} \\
\text { บे } \\
\text { Uे } \\
0 \\
0 \\
0\end{array}$ & 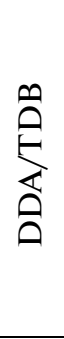 & 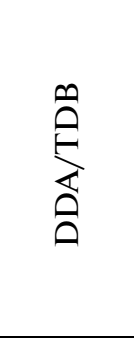 & 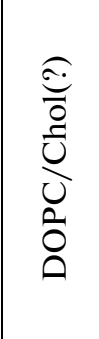 & 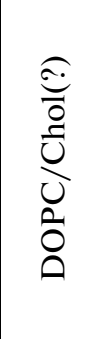 & 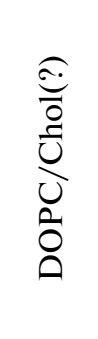 & । & 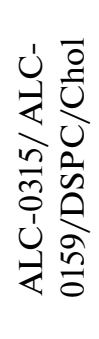 & 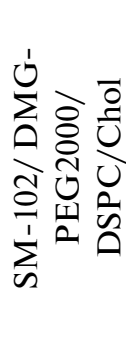 & 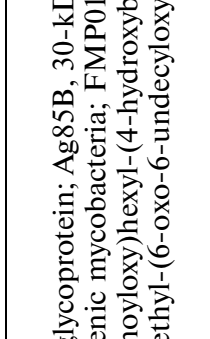 \\
\hline 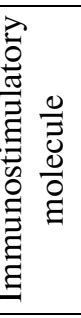 & 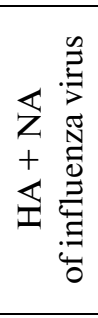 & $\stackrel{\circ}{z}$ & 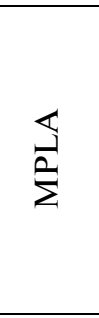 & 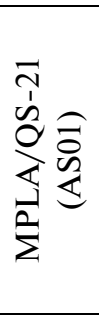 & 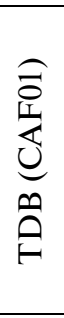 & 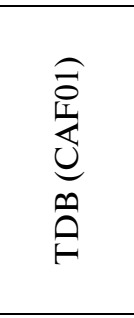 & 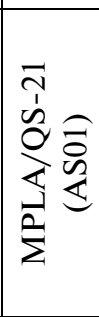 & 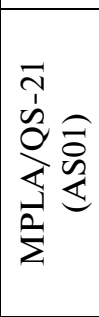 & 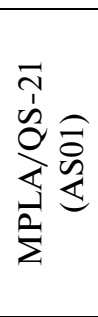 & 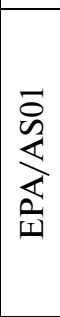 & $\stackrel{\circ}{ }$ & $\stackrel{\circ}{z}$ & 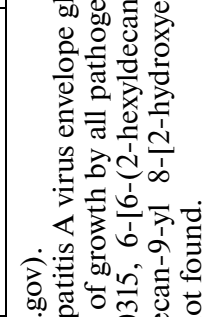 \\
\hline $\begin{array}{l}\tilde{D} \\
\text { 总 } \\
\text { 妾 }\end{array}$ & 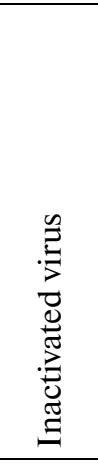 & 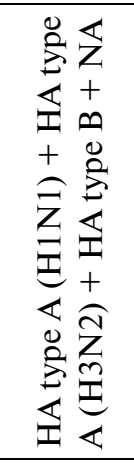 & 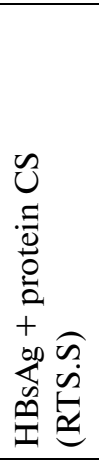 & D) & 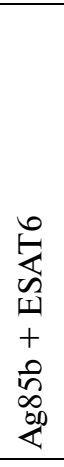 & 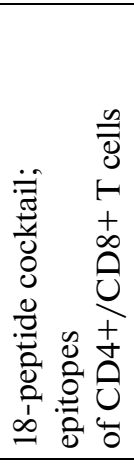 & 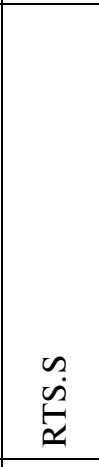 & $\frac{\tilde{D}}{\sum_{I I}^{\circ}}$ & $\begin{array}{l}\vec{n} \\
\underline{\underline{n}} \\
\underline{\underline{n}}\end{array}$ & 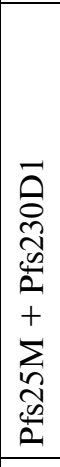 & 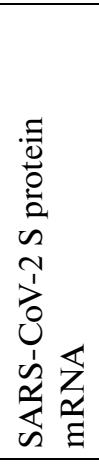 & 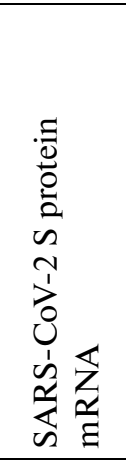 & 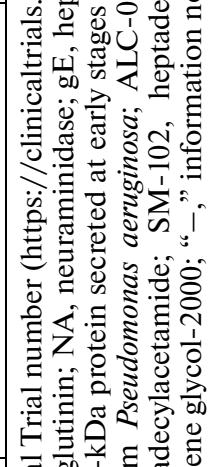 \\
\hline 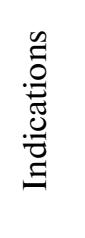 & 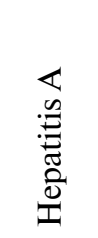 & $\begin{array}{l}\stackrel{\widetilde{\Xi}}{\Xi} \\
\stackrel{\Xi}{\Xi} \\
\Xi\end{array}$ & $\frac{\frac{\pi}{\pi}}{\frac{\pi}{\pi}}$ & 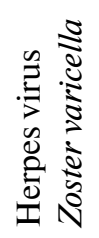 & 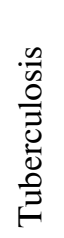 & 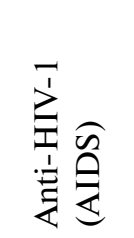 & $\frac{\frac{\pi}{\pi}}{\frac{\pi}{\pi}}$ & $\frac{\frac{\pi}{\tilde{E}}}{\frac{\pi}{\pi}}$ & $\frac{\frac{\pi}{\tilde{E}}}{\frac{\pi}{\pi}}$ & $\mid \frac{\pi}{\tilde{\pi}}$ & $\sum_{0}^{\frac{9}{1}}$ & $\sum_{0}^{\frac{9}{1}}$ & 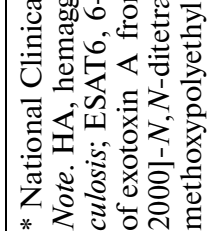 \\
\hline
\end{tabular}




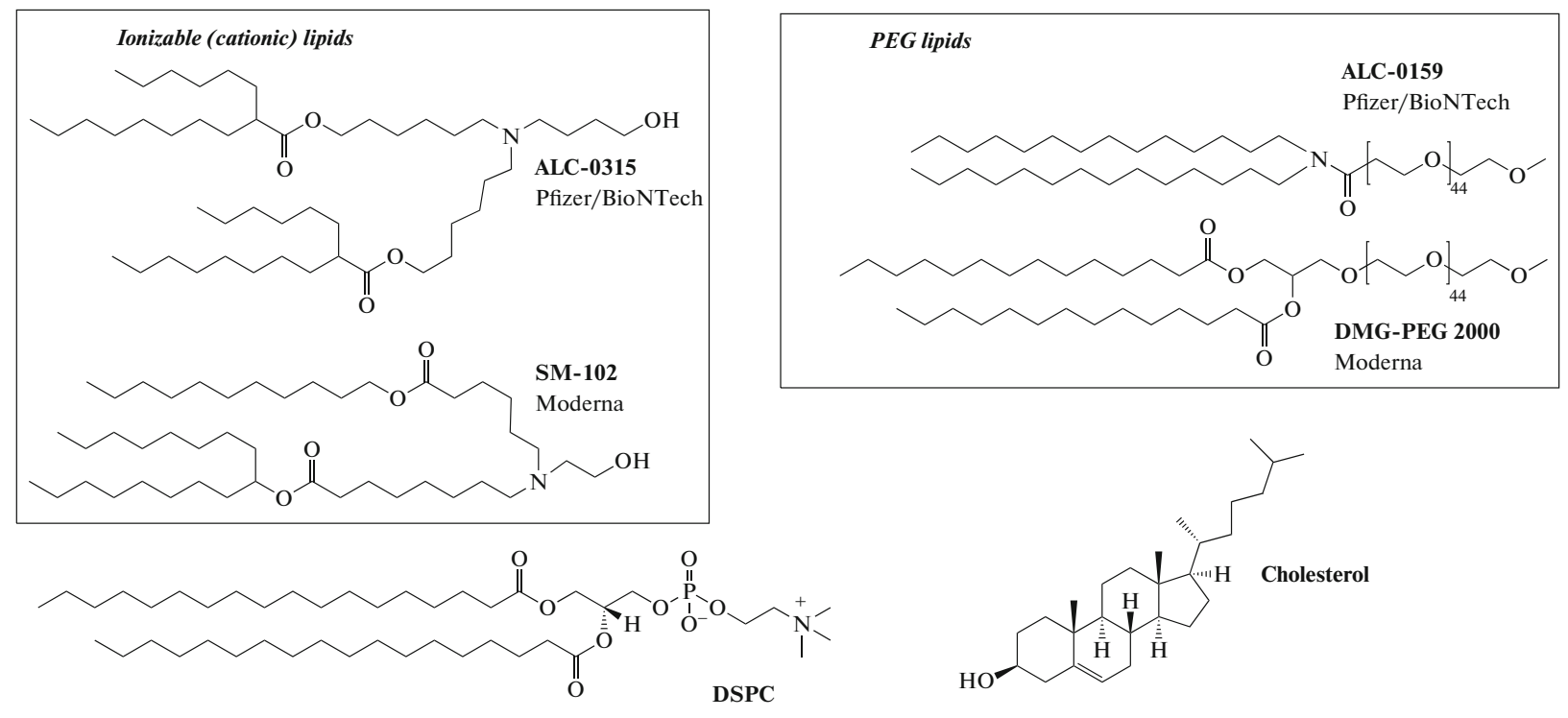

Fig. 6. Lipid components of mRNA vaccines by Pfizer/BioNTech and Moderna (according to the review [131] and online resources https://www.cas.org/resource/blog/understanding-nanotechnology-covid-19-vaccines).

(a)

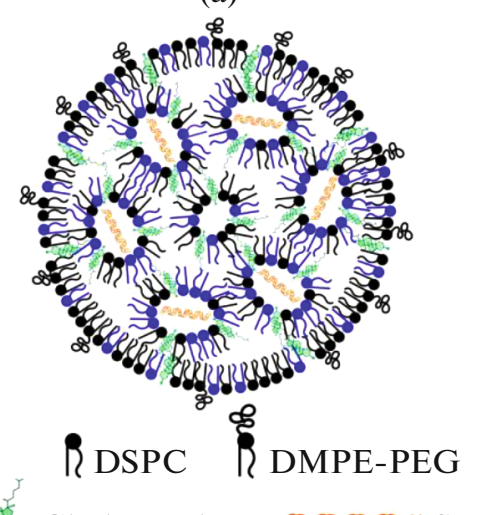

(b)

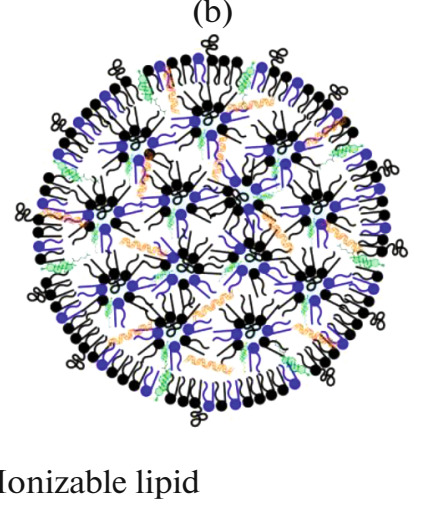

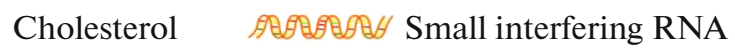

Fig. 7. Variants of LNP structures with siRNAs (according to the review [131] and online resources https://www.cas.org/ resource/blog/understanding-nanotechnology-covid-19-vaccines). Similar structures are predicted for LNPs with mRNA.

We only very briefly dwelled on the burning and breakthrough topic of mRNA-LNP vaccines, which has already been covered in many publications, both review and experimental research. For example, the review [134] discusses that the mechanism of action of mRNA-LNP vaccines is not fully understood, considers the immunological aspects of the inappropriate action of vaccine components that can provoke unwanted side effects, and possible ways to overcome these risks, including through targeting of dendritic cells. The advent of the first mRNA vaccines stimulated research on the development of other lipidRNA complex constructs with potential benefits. For example, in order to optimize the technology of the vaccine production and storage, RNA has been pro- posed to be complexed with preliminarily prepared liposomes immediately before immunization, and it was shown that such complexes are not inferior in immunogenicity to liposomes with encapsulated RNAs [135, 136] (Fig. 8).

\section{CONCLUSIONS}

After many years of experimentation, liposomes as delivery systems for vaccines and adjuvants are widely used in both preclinical and clinical studies due to such unique properties as biocompatibility, high level of safety, and the ability to create a variety of structures by varying the components of the lipid matrix. In recent years, interest in the development of liposome- 

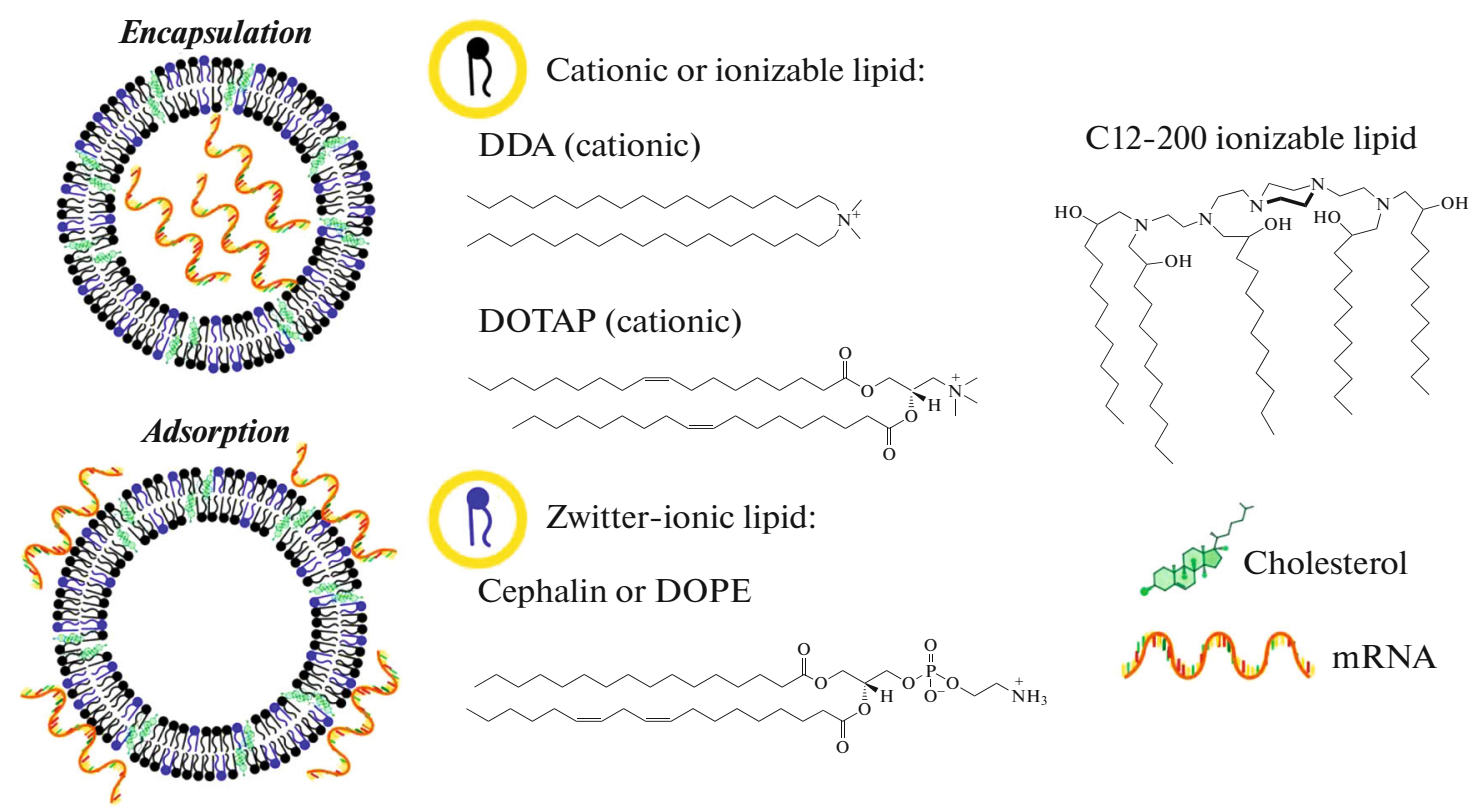

Cephalin or DOPE
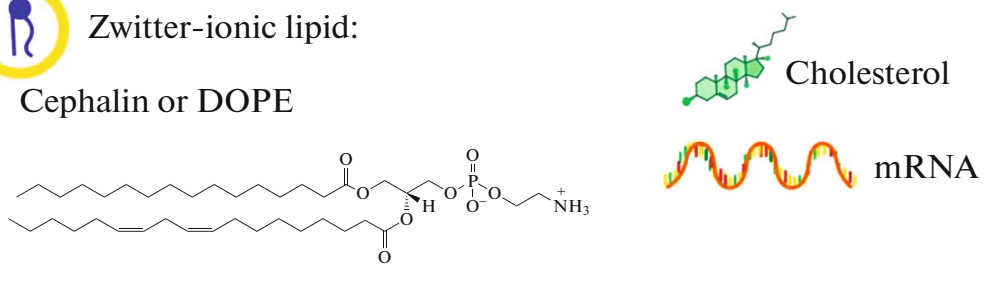

Fig. 8. Schematic representation of liposomes with encapsulated or surface-adsorbed mRNA molecules and structures of cationic and ionizable lipids.

based vaccines has grown, which is associated with the improvement of the technology for the industrial production of various high-purity lipids suitable for parenteral administration [137]. It is also fundamentally important that new technologies and equipment have appeared for the industrial production of liposomal preparations $[7,116]$.

When developing liposomal vaccines, it is necessary to take into account the mechanisms of the functioning of the body's immune system (innate and adaptive immunity). Introduction of ligands to relevant receptors involved in the recognition of PAMPs (innate immunity) into the liposomal constructs can significantly enhance the immune response to the antigen delivered by liposomes. The PRRs specifically contribute to signaling processes leading to the activation and differentiation of helper $\mathrm{T}$ cells, which ultimately induce an adaptive immune response mediated by CD8+ T lymphocytes and antibody producing B cells. The size of liposomes, their charge, morphology (lamellarity), and the phase state of the bilayer, which depend on the lipid composition, can influence antigen presentation and interactions with APCs, although the results of studies on the trends of such influence are often contradictory. Therefore, in each specific case, special studies should be carried out. The use of secondary lipid messengers as part of a lipid matrix provides additional opportunities for enhancing or correcting molecular pathways for activating the immune response. As for the localization of the antigen in the vaccine-whether it is encapsulated in liposomes or adsorbed on the surface - there is no definite answer here. The results of many preclinical (e.g.,
[138]) and clinical studies indicate that even simple mixing of an antigen with liposomes enhances immunoreactivity. Indeed, clinically used Mosquirix ${ }^{\circledR}$ and Shingrix ${ }^{\circledR}$ vaccines (as well as numerous aluminumcontaining vaccines) are obtained by simply mixing antigens with the AS01 liposomal complex [139]. Nevertheless, it is difficult to deny the fact that this method of producing vaccine preparations is most likely dictated by the need to simplify the technology of their production and subsequent storage (and reduce their cost). It is likely that the immunogenicity of these vaccines would be further increased if stable preparations with encapsulated or adsorbed antigens were used.

And yet, despite the difficulties in the production of such complex preparations as liposomal, many problems of creating stable and reproducible constructs have already been solved, the requirements for them have been established by the regulatory authorities. It can be expected that in the coming years there will be many new vaccines based on lipid complexes to fight dangerous infectious diseases.

\section{ACKNOWLEDGMENTS}

The work was supported by the Russian Foundation for Basic Research (project no. 20-04-60478) and the research program planned in Shemyakin-Ovchinnikov Institute of Bioorganic Chemistry RAS (project no. FM4FM-20190026). 


\section{COMPLIANCE WITH ETHICAL STANDARDS}

The authors declare they have no conflicts of interests.

The work is a review of publications by third authors performed in accordance with all applicable international, national, and/or institutional principles for animal care and use. The review contains no description of own studies involving animals or humans as subjects of the study.

\section{REFERENCES}

1. Delany I., Rappuoli R., De Gregorio E. 2014. Vaccines for the 21st century. EMBO Mol. Med. 6 (6), 708-720.

2. De Temmerman M-L., Rejman J., Demeester J., Irvine D.J., Gander B., De Smedt S.C. 2011. Particulate vaccines: On the quest for optimal delivery and immune response. Drug Discov. Today. 16 (13-14), 569582.

3. Reed S., Orr M. and Fox C. 2013. Key roles of adjuvants in modern vaccines. Nat. Med. 19, 1597-1608.

4. Allison A., Gregoriadis G. 1974. Liposomes as immunological adjuvants. Nature. 252 (5480), 252.

5. Allison A., Gregoriadis G. 1976. Liposomes as immunological adjuvants. Recent Results Cancer Res. 56, $58-64$.

6. Schwendener R.A. 2014. Liposomes as vaccine delivery systems: A review of the recent advances. Ther. Adv. Vaccines. 2 (6), 159-182.

7. Perrie Y., Crofts F., Devitt A., Griffiths H. R., Kastner E., Nadella V. 2016. Designing liposomal adjuvants for the next generation of vaccines. Adv. Drug. Deliv. Rev. 99 (Pt A), 85-96.

8. Tandrup Schmidt S., Foged C., Korsholm K. S., Rades T., Christensen D. 2016. Liposome-based adjuvants for subunit vaccines: Formulation strategies for subunit antigens and immunostimulators. Pharmaceutics. 8 (1), 7.

9. Nisini R., Poerio N., Mariotti S., De Santis F., Fraziano M. 2018. The multirole of liposomes in therapy and prevention of infectious diseases. Front. Immunol. 9, 155.

10. Bernasconi V., Norling K., Bally M., Höök F., Lycke N.Y. 2016. Mucosal vaccine development based on liposome technology. J. Immunol. Res. 2016, 5482087.

11. Usonis V., Bakasénas V., Valentelis R., Katiliene G., Vidzeniene D., Herzog,C. 2003. Antibody titres after primary and booster vaccination of infants and young children with a virosomal hepatitis A vaccine (Epaxal). Vaccine. 21 (31), 4588-4592.

12. https://www.shingrix.com/index.html

13. Torchilin V.P. 2005. Recent advances with liposomes as pharmaceutical carriers. Nat. Rev. Drug Discov. 4 (2), 145-160.

14. Watson D., Endsley A., Huang L. 2012. Design considerations for liposomal vaccines: Influence of formulation parameters on antibody and cell-mediated immune responses to liposome associated antigens. Vaccine. 30, 2256-2272.

15. Zahednezhad F., Saadat M., Valizadeh H., ZakeriMilani P., Baradaran B. 2019. Liposome and immune system interplay: Challenges and potentials. J. Control. Release. 305, 194-209.
16. Szebeni J., Muggia F., Gabizon A., Barenholz Y. 2011. Activation of complement by therapeutic liposomes and other lipid excipient-based therapeutic products: Prediction and prevention. Adv. Drug Deliv. Rev. 63, 1020-1030.

17. Jung S., Unutmaz D., Wong P., Sano G., De los Santos K., Sparwasser T., Wu S., Vuthoori S., Ko K., Zavala F., Pamer E.G., Littman D.R., Lang R.A. 2002. In vivo depletion of $\mathrm{CD} 11 \mathrm{c}^{+}$dendritic cells abrogates priming of $\mathrm{CD}^{+} \mathrm{T}$ cells by exogenous cell-associated antigens. Immunity. 17 (2), 211-220.

18. Kawai T., Akira S. 2010. The role of patternrecognition receptors in innate immunity: Update on Toll-like receptors. Nat. Immunol. 11, 373-384.

19. Banchereau J., Palucka A.K. 2005. Dendritic cells as therapeutic vaccines against cancer. Nat. Rev. Immunol. 5 (4), 296-306.

20. Bevan M.J. 1976. Cross-priming for a secondary cytotoxic response to minor $\mathrm{H}$-antigens with $\mathrm{H}-2$ congenic cells which do not cross-react in cytotoxic assay. J. Exp. Med. 143, 1283-1288.

21. Joffre O.P., Segura E., Savina A., Amigorena S. 2012. Cross-presentation by dendritic cells. Nat. Rev. Immunol. $12(8), 557-569$.

22. Zehner M., Marschall A. L., Bos E., Schloetel J. G., Kreer C., Fehrenschild D., Limmer A., Ossendorp F., Lang T., Koster A. J., Dübel S., Burgdorf S. 2015. The translocon protein Sec61 mediates antigen transport from endosomes in the cytosol for cross-presentation to $\mathrm{CD} 8^{+} \mathrm{T}$ cells. Immunity. 42 (5), 850-863.

23. Yeung T., Ozdamar B., Paroutis P., Grinstein S. 2006. Lipid metabolism and dynamics during phagocytosis. Curr. Opin. Cell. Biol. 18 (4), 429-437.

24. Yeung T., Grinstein S. 2007. Lipid signaling and the modulation of surface charge during phagocytosis. Immunol. Rev. 219, 17-36.

25. Bohdanowicz M., Grinstein S. 2013. Role of phospholipids in endocytosis, phagocytosis, and macropinocytosis. Physiol. Rev. 93 (1), 69-106.

26. Steinberg B.E., Grinstein S. 2008. Pathogen destruction versus intracellular survival: The role of lipids as phagosomal fate determinants. J. Clin. Invest. 118 (6), 2002-2011.

27. Anes E., Kuhnel M.P., Bos E., Moniz-Pereira J., Habermann A., Griffiths G. 2003. Selected lipids activate phagosome actin assembly and maturation resulting in killing of pathogenic mycobacteria. Nat. Cell Biol. 5 (9), 793-802.

28. Garg S.K., Valente E., Greco E., Santucci M.B., De Spirito M., Papi M., Bocchino M., Saltini C., Fraziano M. 2006. Lysophosphatidic acid enhances antimycobacterial activity both in vitro and ex vivo. Clin. Immunol. 121 (1), 23-28.

29. Garg S.K., Volpe E., Palmieri G., Mattei M., Galati D., Martino A., Piccioni M.S., Valente E., Bonanno E., De Vito P., Baldini P.M., Spagnoli L.G., Colizzi V., Fraziano M. 2004. Sphingosine 1-phosphate induces antimicrobial activity both in vitro and in vivo. $J$. Infect. Dis. 189 (11), 2129-2138.

30. Greco E., Santucci M.B., Sali M., De Angelis F.R., Papi M., De Spirito M., Delogu G., Colizzi V., Fraziano M. 2010. Natural lysophospholipids reduce Myco- 
bacterium tuberculosis-induced cytotoxicity and induce anti-mycobacterial activity by a phagolysosome maturation-dependent mechanism in A549 type II alveolar epithelial cells. Immunology. 129 (1), 125-132.

31. Greco E., Quintiliani G., Santucci M.B., Serafino A., Ciccaglione A.R., Marcantonio C., Papi M., Maulucci G., Delogu G., Martino A., Goletti D., Sarmati L., Andreoni M., Altieri A., Alma M., Caccamo N., Di Liberto D., De Spirito M., Savage N.D., Nisini R., Fraziano M. 2012. Janus-faced liposomes enhance antimicrobial innate immune response in Mycobacterium tuberculosis infection. Proc. Natl. Acad. Sci. USA. 109 (21), E1360-E1368.

32. Poerio N., Bugli F., Taus F., Santucci M.B., Rodolfo C., Cecconi F., Torelli R., Varone F., Inchingolo R., Majo F., Lucidi V., Mariotti S., Nisini R., Sanguinetti M., Fraziano M. 2017. Liposomes loaded with bioactive lipids enhance antibacterial innate immunity irrespective of drug resistance. Sci. Rep. 7, 45120.

33. van Houte A.J., Snippe H., Schmitz M.G., Willers J.M. 1981. Characterization of immunogenic properties of haptenated liposomal model membranes in mice. V. Effect of membrane composition on humoral and cellular immunogenicity. Immunology. 44 (3), 561-568.

34. Szebeni J., Baranyi L., Savay S., Milosevits J., Bodo M., Bunger R., Alving C.R. 2003. The interaction of liposomes with the complement system: In vitro and in vivo assays. Methods Enzymol. 373,136-154.

35. Banerjee S., Ghosh J., Sen S., Guha R., Dhar R., Ghosh M., Datta S., Raychaudhury B., Naskar K., Haldar A.K., Lal C.S., Pandey K., Das V.N., Das P., Roy S. 2009. Designing therapies against experimental visceral leishmaniasis by modulating the membrane fluidity of antigen-presenting cells. Infect. Immun. 77, 2330-2342.

36. Ghosh J., Guha R., Das S., Roy S. 2014. Liposomal cholesterol delivery activates the macrophage innate immune arm to facilitate intracellular Leishmania donovani killing. Infect. Immun. 82 (2), 607-617.

37. Mohanan D., Slütter B., Henriksen-Lacey M., Jiskoot W., Bouwstra J.A., Perrie Y., Kündig T.M., Gander B., Johansen P. 2010. Administration routes affect the quality of immune responses: A cross-sectional evaluation of particulate antigen-delivery systems. J. Control. Release. 147, 342-349.

38. Oussoren C., Zuidema J., Crommelin D.J.A., Storm G. 1997. Lymphatic uptake and biodistribution of liposomes after subcutaneous injection. II. Influence of liposomal size, lipid composition and lipid dose. Biochim. Biophys. Acta. 1328, 261-272.

39. Carstens M.G., Camps M.G.M., Henriksen-Lacey M., Franken K., Ottenhoff T.H.M., Perrie Y., Bouwstra J.A., Ossendorp F., Jiskoot W. 2011. Effect of vesicle size on tissue localization and immunogenicity of liposomal DNA vaccines. Vaccine. 29, 4761-4770.

40. Ghaffar K.A., Giddam A.K., Zaman M., Skwarczynski M., Toth I. 2014. Liposomes as nanovaccine delivery systems. Curr. Top. Med. Chem. 14 (9), 1194-1208.

41. Bartlett S, Skwarczynski M, Toth I. 2020. Lipids as activators of innate immunity in peptide vaccine delivery. Curr. Med. Chem. 27 (17), 2887-2901.
42. Brewer J.M., Pollock K.G., Tetley L., Russell D.G. 2004. Vesicle size influences the trafficking, processing, and presentation of antigens in lipid vesicles. J. Immunol. 173 (10), 6143-6150.

43. Ghaffar K.A., Marasini N., Giddam A.K., Batzloff M.R., Good M.F., Skwarczynski M., Toth I. 2016. The role of size in development of mucosal liposome-lipopeptide vaccine candidates against group A Streptococcus. Med. Chem. 13 (1), 22-27.

44. Mann J.F., Shakir E., Carter K.C., Mullen A.B., Alexander J., Ferro V.A. 2009. Lipid vesicle size of an oral influenza vaccine delivery vehicle influences the Th1/ Th2 bias in the immune response and protection against infection. Vaccine. 27 (27), 3643-3649.

45. Brewer J.M., Tetley L., Richmond J., Liew F.Y., Alexander J. 1998. Lipid vesicle size determines the Th1 or Th2 response to entrapped antigen. J. Immunol. 161, 4000-4007.

46. Badiee A., Khamesipour A., Samiei A., Soroush D., Shargh V.H., Kheiri M.T., Barkhordari F., Robert Mc Master W., Mahboudi F., Jaafari M.R. 2012. The role of liposome size on the type of immune response induced in balb/c mice against leishmaniasis: Rgp63 as a model antigen. Exp. Parasitol. 132, 403-409.

47. Manolova V., Flace A., Bauer M., Schwarz K., Saudan P., Bachmann M.F. 2008. Nanoparticles target distinct dendritic cell populations according to their size. Eur. J. Immunol. 38 (5), 1404-1413.

48. Henriksen-Lacey M., Devitt A., Perrie Y. 2011. The vesicle size of dda:Tdb liposomal adjuvants plays a role in the cell-mediated immune response but has no significant effect on antibody production. J. Control. Release. 154, 131-137.

49. Tanaka Y., Taneichi M., Kasai M., Kakiuchi T., Uchida T. 2010. Liposome-coupled antigens are internalized by antigen-presenting cells via pinocytosis and cross-presented to CD8 T cells. PLoS One. 5 (12), e 15225 .

50. Christensen D., Henriksen-Lacey M., Kamath A.T., Lindenstrøm T., Korsholm K.S., Christensen J.P., Rochat A.F., Lambert P.H., Andersen P., Siegrist C.A., Perrie Y., Agger E.M. 2012. A cationic vaccine adjuvant based on a saturated quaternary ammonium lipid have different in vivo distribution kinetics and display a distinct CD4 T cell-inducing capacity compared to its unsaturated analog. J. Control. Release. 160 (3), 468-476.

51. Werninghaus K., Babiak A., Gross O., Hölscher C., Dietrich H., Agger E.M., Mages J., Mocsai A., Schoenen H., Finger K., Nimmerjahn F., Brown G.D., Kirschning C., Heit A., Andersen P., Wagner H., Ruland J., Lang R. 2009. Adjuvanticity of a synthetic cord factor analogue for subunit Mycobacterium tuberculosis vaccination requires FcRgamma-Syk-Card9-dependent innate immune activation. J. Exp. Med. 206 (1), 89-97.

52. Harding C.V., Collins D.S., Kanagawa O., Unanue E.R. 1991. Liposome-encapsulated antigens engender lysosomal processing for class II MHC presentation and cytosolic processing for class I presentation. J. Immunol. 147 (9), 2860-2863.

53. Miller C.R., Bondurant B., McLean S.D., McGovern K.A., O’Brien D.F. 1998. Liposome-cell interactions in vitro: Effect of liposome surface charge on the 
binding and endocytosis of conventional and sterically stabilized liposomes. Biochemistry. 37, 12875-12883.

54. Henriksen-Lacey M., Christensen D., Bramwell V.W., Lindenstrøm T., Agger E.M., Andersen P., Perrie Y. 2010. Liposomal cationic charge and antigen adsorption are important properties for the efficient deposition of antigen at the injection site and ability of the vaccine to induce a CMI response. J. Control. Release. 145 (2), 102-108.

55. Perrie Y., Obrenovic M., McCarthy D., Gregoriadis G. 2002. Liposome (Lipodine)-mediated DNA vaccination by the oral route. J. Liposome Res. 12 (1-2), 185-197.

56. Nel A.E., Madler L., Velegol D., Xia T., Hoek E.M.V., Somasundaran P., Klaessig F., Castranova V., Thompson M. 2009. Understanding biophysicochemical interactions at the nano-bio interface. Nat. Mater. 8, 543-557.

57. Hussain M.J., Wilkinson A., Bramwell V.W.,Christensen D., Perrie Y. 2014. Th1 immune responses can be modulated by varying dimethyldioctadecylammonium and distearoyl-sn-glycero-3-phosphocholine content in liposomal adjuvants. J. Pharm. Pharmacol. 66 (3), 358-366.

58. Korsholm K.S., Petersen R.V., Agger E.M., Andersen P. 2010. T-helper 1 and T-helper 2 adjuvants induce distinct differences in the magnitude, quality and kinetics of the early inflammatory response at the site of injection. Immunology. 129, 75-86.

59. Wahab M.S., Hair-Bejo M., Omar A.R., Ideris A. 2017. Hatchery vaccination using liposomes as vaccine delivery against infectious bursal disease in broiler chickens. J. Anim. Vet. Adv. 16, 122-128.

60. Hoffmann P.R., Kench J.A., Vondracek A., Kruk E., Daleke D.L., Jordan M., Marrack P., Henson P.M., Fadok V.A. 2005. Interaction between phosphatidylserine and the phosphatidylserine receptor inhibits immune responses in vivo. J. Immunol. 174 (3), 13931404.

61. Ichihashi T., Satoh T., Sugimoto C., Kajino K. 2013. Emulsified phosphatidylserine, simple and effective peptide carrier for induction of potent epitope-specific T cell responses. PLoS One. 8 (3), e60068.

62. Benne N., van Duijn J., Lozano Vigario F., Leboux R.J.T., van Veelen P., Kuiper J., Jiskoot W., Slütter B. 2018. Anionic 1,2-distearoyl-sn-glycero-3phosphoglycerol (DSPG) liposomes induce antigenspecific regulatory $\mathrm{T}$ cells and prevent atherosclerosis in mice. J. Control. Release. 291, 135-146.

63. Benne N., Leboux R.J.T., Glandrup M., van Duijn J., Lozano Vigario F., Neustrup M.A., Romeijn S., Galli F., Kuiper J., Jiskoot W., Slütter B. 2020. Atomic force microscopy measurements of anionic liposomes reveal the effect of liposomal rigidity on antigen-specific regulatory $\mathrm{T}$ cell responses. J. Control. Release. 318, 246-255.

64. Liu Y., Janeway C.A. 1991. Microbial induction of costimulatory activity for CD4 T-cell growth. Int. Immunol. 3 (4), 323-332.

65. Gayed P.M. 2011. Toward a modern synthesis of immunity: Charles A. Janeway Jr. and the immunolo- gist's dirty little secret. Yale J. Biol. Med. 84 (2), 131138.

66. Guy B. 2007. The perfect mix: Recent progress in adjuvant research. Nat. Rev. Microbiol. 5, 505-517.

67. Geijtenbeek T.B.H., Gringhuis S.I. 2009. Signalling through c-type lectin receptors: Shaping immune responses. Nat. Rev. Immunol. 9, 465-479.

68. Maisonneuve C., Bertholet S., Philpott D.J., De Gregorio E. 2014. Unleashing the potential of Nod- and Toll-like agonists as vaccine adjuvants. Proc. Natl. Acad. Sci. USA. 111, 12294-12299.

69. Akira S., Uematsu S., Takeuchi O. 2006. Pathogen recognition and innate immunity. Cell. 124, 783-801.

70. Agrawal S., Agrawal A., Doughty B., Gerwitz A., Blenis J., Van Dyke T., Pulendran B. 2003. Cutting edge: Different toll-like receptor agonists instruct dendritic cells to induce distinct $\mathrm{Th}$ responses via differential modulation of extracellular signal-regulated kinasemitogen-activated protein kinase and c-fos. J. Immunol. 171, 4984-4989.

71. Medzhitov R. 2001. Toll-like receptors and innate immunity. Nat. Rev. Immunol. 1, 135-145.

72. Jin B., Sun T., Yu X.-H., Liu C.-Q., Yang Y.-X., Lu P., Fu S.-F., Qiu H.-B., Yeo A.E.T. 2010. Immunomodulatory effects of dsRNA and its potential as vaccine adjuvant. J. Biomed. Biotechnol. 2010, 690438.

73. Hemmi H., Takeuchi O., Kawai T., Kaisho T., Sato S., Sanjo H., Matsumoto M., Hoshino K., Wagner H., Takeda K., Akira S. 2000. A Toll-like receptor recognizes bacterial DNA. Nature. 408, 740-745.

74. Lee Y., Lee Y.S., Cho S.Y., Kwon H.J. 2015. Perspective of peptide vaccine composed of epitope peptide, CpG-DNA, and liposome complex without carriers. Adv. Protein Chem. Struct. Biol. 99, 75-97.

75. Vabulas R.M., Pircher H., Lipford G.B., Häcker H., Wagner H. 2000. CpG-DNA activates in vivo T cell epitope presenting dendritic cells to trigger protective antiviral cytotoxic $\mathrm{T}$ cell responses. J. Immunol. 164, 2372-2378.

76. Nikoofal-Sahlabadi S., Matbou Riahi M., Sadri K., Badiee A., Nikpoor A.R., Jaafari M.R. 2018. Liposomal CpG-ODN: An in vitro and in vivo study on macrophage subtypes responses, biodistribution and subsequent therapeutic efficacy in mice models of cancers. Eur. J. Pharm. Sci. 119, 159-170.

77. Chatzikleanthous D., Schmidt S.T., Buffi G., Paciello I., Cunliffe R., Carboni F., Romano M.R., O'Hagan D.T., D’Oro U., Woods S., Roberts C.W., Perrie Y., Adamo R. 2020. Design of a novel vaccine nanotechnology-based delivery system comprising CpGODN-protein conjugate anchored to liposomes. J. Control. Release. 323, 125-137.

78. Tafaghodi M., Jaafari M.R., Sajadi Tabassi S.A. 2006. Nasal immunization studies using liposomes loaded with tetanus toxoid and CpG-ODN. Eur. J. Pharm. Biopharm. 64, 138-145.

79. Morrey J.D., Motter N.E., Chang S., Fairman J. 2011. Breaking B and T cell tolerance using cationic lipidDNA complexes (CLDC) as a vaccine adjuvant with hepatitis B virus (HBV) surface antigen in transgenic mice expressing HBV. Antiviral Res. 90 (3), 227-230. 
80. Jain V., Vyas S.P., Kohli D.V. 2009. Well-defined and potent liposomal hepatitis B vaccines adjuvanted with lipophilic MDP derivatives. Nanomedicine. 5 (3), 334344.

81. Johnston D., Zaidi B., Bystryn J.C. 2007. TLR7 imidazoquinoline ligand $3 \mathrm{M}-019$ is a potent adjuvant for pure protein prototype vaccines. Cancer Immunol. Immun. 56, 1133-1141.

82. Schulz O., Diebold S.S., Chen M., Näslund T.I., Nolte M.A., Alexopoulou L., Azuma Y.T., Flavell R.A., Liljeström P., Reis e Sousa C. 2005. Toll-like receptor 3 promotes cross-priming to virus infected cells. Nature. 433, 887-892.

83. Zaks K., Jordan M., Guth A., Sellins K., Kedl R., Izzo A., Bosio C., Dow S. 2006. Efficient immunization and cross-priming by vaccine adjuvants containing TLR3 or TLR9 agonists complexed to cationic liposomes. $J$. Immunol. 176, 7335-7345.

84. Alving C.R., Rao M., Steers N.J., Matyas G.R., Mayorov A.V. 2012. Liposomes containing lipid A: An effective, safe, generic adjuvant system for synthetic vaccines. Expert Rev. Vaccines. 11 (6), 733-744.

85. Vandepapelière P., Horsmans Y., Moris P., Van Mechelen M., Janssens M., Koutsoukos M., Van Belle P., Clement F., Hanon E., Wettendorff M., Garçon N., Leroux-Roels G. 2008. Vaccine adjuvant systems containing monophosphoryl lipid A and QS-21 induce strong and persistent humoral and $\mathrm{T}$ cell responses against hepatitis B surface antigen in healthy adult volunteers. Vaccine. 26, 1375-1386.

86. Richards R.L., Rao M., Wassef N.M., Glenn G.M., Rothwell S.W., Alving C.R. 1998. Liposomes containing lipid A serve as an adjuvant for induction of antibody and cytotoxic T-cell responses against RTS,S malaria antigen. Infect. Immun. 66 (6), 2859-2865.

87. Stoute J.A., Slaoui M., Heppner D.G., Momin P., Kester K.E., Desmons P., Wellde B.T., Garçon N., Krzych U., Marchand M. 1997. A preliminary evaluation of a recombinant circumsporozoite protein vaccine against Plasmodium falciparum malaria. N. Engl. J. Med. 336, 86-91.

88. Lacaille-Dubois M.A. 2019. Updated insights into the mechanism of action and clinical profile of the immunoadjuvant QS-21: A review. Phytomedicine. 60, 152905.

89. Marty-Roix R., Vladimer G.I., Pouliot K., Weng D., Buglione-Corbett R., West K., MacMicking J.D., Chee J.D., Wang S., Lu S., Lien E. 2016. Identification of QS-21 as an inflammasome-activating molecular component of saponin adjuvants. J. Biol. Chem. 291 (3), 1123-1136.

90. Genito C.J., Beck Z., Phares T.W., Kalle F., Limbach K.J., Stefaniak M.E., Patterson N.B., Bergmann-Leitner E.S., Waters N.C., Matyas G.R., Alving C.R., Dutta S. 2017. Liposomes containing monophosphoryl lipid A and QS-21 serve as an effective adjuvant for soluble circumsporozoite protein malaria vaccine FMP013. Vaccine. 35 (31), 3865-3874.

91. Cawlfield A., Genito C.J., Beck Z., BergmannLeitner E.S., Bitzer A.A., Soto K., Zou X., Hadiwidjojo S.H., Gerbasi R.V., Mullins A.B., Noe A., Waters N.C., Alving C.R., Matyas G.R., Dutta S. 2019. Safety, toxicity, and immunogenicity of a malaria vac- cine based on the circumsporozoite protein (FMP013) with the adjuvant army liposome formulation containing QS-21 (ALFQ). Vaccine. 37, 3793-3803.

92. Martin M.L., Bitzer A.A., Schrader A., BergmannLeitner E.S., Soto K., Zou X., Beck Z., Matyas G.R., Dutta S. 2019. Comparison of immunogenicity and safety outcomes of a malaria vaccine FMP013/ALFQ in rhesus macaques (Macaca mulatta) of Indian and Chinese origin. Malar. J. 18 (1), 377.

93. A trial for the study of falciparum malaria protein 013 administered via intramuscular injection in healthy adults. https://clinicaltrials.gov/ct2/show/NCT04268420

94. Nagill R., Kaur S. 2010. Enhanced efficacy and immunogenicity of $78 \mathrm{kDa}$ antigen formulated in various adjuvants against murine visceral leishmaniasis. Vaccine. 28 (23), 4002-4012.

95. Bal S.M., Hortensius S., Ding Z., Jiskoot W., Bouwstra J.A. 2011. Co-encapsulation of antigen and toll-like receptor ligand in cationic liposomes affects the quality of the immune response in mice after intradermal vaccination. Vaccine. 29 (5), 1045-1052.

96. Giddam A.K., Zaman M., Skwarczynski M., Toth I. 2012. Liposome-based delivery system for vaccine candidates: Constructing an effective formulation. Nanomedicine (Lond). 7 (12), 1877-1893.

97. Korsholm K.S., Hansen J., Karlsen K., Filskov J., Mikkelsen M., Lindenstrøm T., Schmidt S.T., Andersen P., Christensen D. 2014. Induction of CD8 ${ }^{+}$T-cell responses against subunit antigens by the novel cationic liposomal CAF09 adjuvant. Vaccine. 32 (31), 39273935.

98. Martin-Bertelsen B., Korsholm K.S., Roces C.B., Nielsen M.H., Christensen D., Franzyk H., Yaghmur A., Foged C. 2016. Nano-self-assemblies based on synthetic analogues of mycobacterial monomycoloyl glycerol and DDA: Supramolecular structure and adjuvant efficacy. Mol. Pharmaceutics. 13 (8), 2771-2781.

99. Purcell A.W., McCluskey J., Rossjohn J. 2007. More than one reason to rethink the use of peptides in vaccine design. Nat. Rev. Drug. Discov. 6 (5), 404-414.

100. Ohno S., Kohyama S., Taneichi M., Moriya O., Hayashi H., Oda H., Mori M., Kobayashi A., Akatsuka T., Uchida T., Matsui M. 2009. Synthetic peptides coupled to the surface of liposomes effectively induce SARS coronavirus-specific cytotoxic T lymphocytes and viral clearance in HLA-A*0201 transgenic mice. Vaccine. 27, 3912-3920.

101. Kohyama S., Ohno S., Suda T., Taneichi M., Yokoyama S., Mori M., Kobayashi A., Hayashi H., Uchida T., Matsui M. 2009. Efficient induction of cytotoxic T lymphocytes specific for severe acute respiratory syndrome (SARS)-associated coronavirus by immunization with surface-linked liposomal peptides derived from a non-structural polyprotein 1a. Antiviral Res. 84, $168-177$.

102. Toth I., Danton M., Flinn N., Gibbons W.A. 1993. A combined adjuvant and carrier system for enhancing synthetic peptides immunogenicity utilising lipidic amino acids. Tetrahedron Lett. 34 (24), 3925-3928.

103. Zaman M., Chandrudu S., Giddam A.K., Reiman J., Skwarczynski M., McPhun V., Moyle P.M., Batzloff M.R., Good M.F., Toth I. 2014. Group A streptococ- 
cal vaccine candidate: Contribution of epitope to size, antigen presenting cell interaction and immunogenicity. Nanomedicine (Lond.). 9 (17), 2613-2624.

104. Ghaffar K.A., Marasini N., Giddam A.K., Batzloff M.R., Good M.F., Skwarczynski M., Toth I. 2016. Liposome-based intranasal delivery of lipopeptide vaccine candidates against group A streptococcus. Acta Biomater. 41, 161-168.

105. Beesley J.L., Woolfson D.N. 2019. The de novo design of $\alpha$-helical peptides for supramolecular self-assembly. Curr. Opin. Biotechnol. 58, 175-182.

106. Leboux R.J.T., Benne N., van Os W.L., Bussmann J., Kros A., Jiskoot W., Slütter B. 2021. High-affinity antigen association to cationic liposomes via coiled coilforming peptides induces a strong antigen-specific CD4 ${ }^{+}$T-cell response. Eur. J. Pharm. Biopharm. 158, 96-105.

107. Shao S., Geng J., Ah Yi H., Gogia S., Neelamegham S., Jacobs A., Lovell J.F. 2015. Functionalization of cobalt porphyrin-phospholipid bilayers with His-tagged ligands and antigens. Nat. Chem. 7 (5), 438-446.

108. Huang W.C., Deng B., Lin C., Carter K.A., Geng J., Razi A., He X., Chitgupi U., Federizon J., Sun B., Long C.A., Ortega J., Dutta S., King C.R., Miura K., Lee S.M., Lovell J.F. 2018. A malaria vaccine adjuvant based on recombinant antigen binding to liposomes. Nat. Nanotechnol. 13 (12), 1174-1181.

109. Kaslow D.C., Bathurst I.C., Lensen T., Ponnudurai T., Barr P.J., Keister D.B. 1994. Saccharomyces cerevisiae recombinant Pfs 25 adsorbed to alum elicits antibodies that block transmission of Plasmodium falciparum. Infect. Immun. 62, 5576-5580.

110. Wu Y., Ellis R.D., Shaffer D., Fontes E., Malkin E.M., Mahanty S., Fay M.P., Narum D., Rausch K., Miles A.P., Aebig J., Orcutt A., Muratova O., Song G., Lambert L., Zhu D., Miura K., Long C., Saul A., Miller L.H., Durbin A.P. 2008. Phase 1 trial of malaria transmission blocking vaccine candidates Pfs 25 and Pvs25 formulated with montanide ISA 51. PLoS One. 3, e2636.

111. Platt V., Huang Z., Cao L., Tiffany M., Riviere K., Szoka F.C. 2010. Influence of multivalent nitrilotriacetic acid lipid-ligand affinity on the circulation halflife in mice of a liposome-attached His6-protein. Bioconj. Chem. 21, 892-902.

112. Huang W.C., Deng B., Seffouh A., Ortega J., Long C.A., Suresh R.V., He X., Miura K., Lee S.M., Wu Y., Lovell J.F. 2020. Antibody response of a particle-inducing, liposome vaccine adjuvant admixed with a Pfs230 fragment. NPJ Vaccines. 5 (1), 23.

113. Huang W.C., Zhou S., He X., Chiem K., Mabrouk M.T., Nissly R.H., Bird I.M., Strauss M., Sambhara S., Ortega J., Wohlfert E.A., Martinez-Sobrido L., Kuchipudi S.V., Davidson B.A., Lovell J.F. 2020. SARS-CoV-2 RBD neutralizing antibody induction is enhanced by particulate vaccination. Adv. Mater. 32, 2005637.

114. De Serrano L.O., Burkhart D.J. 2017. Liposomal vaccine formulations as prophylactic agents: Design considerations for modern vaccines. J. Nanobiotechnology. $15(1), 83$.

115. Wang N., Chen M., Wang T. 2019. Liposomes used as a vaccine adjuvant-delivery system: From basics to clinical immunization. J. Control. Release. 303, 130150.

116. Crommelin D.J.A., van Hoogevest P., Storm G. 2020. The role of liposomes in clinical nanomedicine development. What now? Now what? J. Control. Release. 318, 256-263.

117. Bovier P.A. 2008. Epaxal®: A virosomal vaccine to prevent hepatitis A infection. Expert Rev. Vac. 7 (8), 1141-1150.

118. Mischler R., Metcalfe I.C. 2002. Inflexal V a trivalent virosome subunit influenza vaccine: Production. Vaccine. 20 (Suppl 5), B17-B23.

119. Moser C., Muller M., Kaeser M.D., Weydemann U., Amacker M. 2013. Influenza virosomes as vaccine adjuvant and carrier system. Expert Rev. Vac. 12 (7), 779791.

120. Glueck R. Review of intranasal influenza vaccine. 2001. Adv. Drug Deliv. Rev. 51 (1-3), 203-211.

121. Alving C.R., Beck Z., Matyas G.R., Rao M. 2016. Liposomal adjuvants for human vaccines. Expert Opin. Drug Deliv. 13 (6), 807-816.

122. Syed Y.Y. 2018. Recombinant zoster vaccine (Shingrix $^{\circledR}$ ): A review in Herpes zoster. Drugs Aging. 35, 1031-1040.

123. Cunningham A.L., Lal H., Kovac M., Chlibek R., Hwang S.J., Diez-Domingo J., Godeaux O., Levin M.J., McElhaney J.E., Puig-Barbera J., Abeele C.V., Vesikari T., Watanabe D., Zahaf T., Ahonen A., Athan E., Barba-Gomez J.F., Campora L., de Looze F., Downey H.J., Ghesquiere W., Gorfinkel I., Korhonen T., Leung E., McNeil S.A., Oostvogels L., Rombo L., Smetana J., Weckx L., Yeo W., Heineman T.C., Z.O.E.S. Group. 2016. Efficacy of the Herpes zoster subunit vaccine in adults 70 years of age or older. $N$. Engl. J. Med. 375 (11), 1019-1032.

124. Dendouga N., Fochesato M., Lockman L., Mossman S., Giannini S.L. 2012. Cell-mediated immune responses to a varicella-zoster virus glycoprotein $\mathrm{E}$ vaccine using both a TLR agonist and QS-21 in mice. Vaccine. 30 (20), 3126-3135.

125. James S.F., Chahine E.B., Sucher A.J., Hanna C. 2018. Shingrix: The new adjuvanted recombinant Herpes zoster vaccine. Ann. Pharmacother. 52 (7), 673680.

126. van Dissel J.T., Joosten S.A., Hoff S.T., Soonawala D., Prins C., Hokey D.A., O’Dee D.M., Graves A., Thierry-Carstensen B., Andreasen L.V., Ruhwald M., de Visser A.W., Agger E.M., Ottenhoff T.H., Kromann I., Andersen P. 2014. A novel liposomal adjuvant system, caf01, promotes long-lived mycobacterium tuberculosis-specific t-cell responses in human. Vaccine. 32, 7098-7107.

127. Román V.R., Jensen K.J., Jensen S.S., Leo-Hansen C., Jespersen S., da Silva Té D., Rodrigues C.M., Janitzek C.M., Vinner L., Katzenstein T.L., Andersen P., Kromann I., Andreasen L.V., Karlsson I., Fomsgaard A. 2013. Therapeutic vaccination using cationic liposome-adjuvanted HIV type 1 peptides representing HLA-supertype-restricted subdominant $T$ cell epitopes: Safety, immunogenicity, and feasibility in guinea-bissau. AIDS Res. Hum. Retrovir. 29, 1504-1512. 
128. Olotu A., Fegan G., Wambua J., Nyangweso G., Leach A., Lievens M., Kaslow D.C., Njuguna P., Marsh K., Bejon P. 2016. Seven-year efficacy of RTS,S/AS01 malaria vaccine among young African children. N. Engl. J. Med. 374 (26), 2519-2529.

129. Tenchov R., Bird R., Curtze A.E., Zhou Q. 2021. Lipid nanoparticles - from liposomes to mRNA vaccine delivery, a landscape of research diversity and advancement. ACS Nano. https://doi.org/10.1021/acsnano.1c04996

130. Szoka F.C., Xu Y., Zelphati O. 1997. How are nucleic acids released in cells from cationic lipid-nucleic acid complexes? Adv. Drug Deliv. Rev. 24 (2-3), 291-291.

131. Schoenmaker L., Witzigmann D., Kulkarni J.A., Verbeke R., Kersten G., Jiskoot W., Crommelin D.J.A. 2021. mRNA-lipid nanoparticle COVID-19 vaccines: Structure and stability. Int. J. Pharm. 601, 120586.

132. Viger-Gravel J., Schantz A., Pinon A.C., Rossini A.J., Schantz S., Emsley L. 2018. Structure of lipid nanoparticles containing siRNA or mRNA by dynamic nuclear polarization-enhanced NMR spectroscopy. $J$. Phys. Chem. B. 122 (7), 2073-2081.

133. Brader M.L., Williams S.J., Banks J.M., Hui W.H., Zhou Z.H., Jin L. 2021. Encapsulation state of messenger RNA inside lipid nanoparticles. Biophys. $J$. https://doi.org/10.1016/j.bpj.2021.03.012
134. Igyártó B.Z., Jacobsen S., Ndeupen S. 2021. Future considerations for the mRNA-lipid nanoparticle vaccine platform. Curr. Opin. Virol. 48, 65-72.

135. Blakney A.K., McKay P.F., Yus B.I., Aldon Y., Shattock R.J. 2019. Inside out: Optimization of lipid nanoparticle formulations for exterior complexation and in vivo delivery of saRNA. Gene Therapy. 26, 363372.

136. Blakney A.K., Deletic P., McKay P.F., Bouton C.R., Ashford M., Shattock R.J., Sabirsh A. 2021. Effect of complexing lipids on cellular uptake and expression of messenger RNA in human skin explants. J. Control. Release. 330, 1250-1261.

137. Drescher S., van Hoogevest P. 2020. The phospholipid research center: Current research in phospholipids and their use in drug delivery. Pharmaceutics. 12 (12), 1235.

138. Yanasarn N., Sloat B.R., Cui Z. 2011. Negatively charged liposomes show potent adjuvant activity when simply admixed with protein antigens. Mol. Pharm. 8 (4), 1174-1185.

139. Weinberger B. 2018. Adjuvant strategies to improve vaccination of the elderly population. Curr. Opin. Pharmacol. 41, 34-41.

Translated by N. Onishchenko 